\title{
NUMERICAL ASSESSMENT OF A SPACE-CONSTRAINED VENTING SYSTEM WITH MULTI-CHAMBER PLUG MUFFLERS BY GA METHOD
}

Chiu Min-Chie

Department of Automatic Control Engineering, Chungchou Institute of Technology 6, Lane 2, Sec. 3, Shanchiao Rd., Yuanlin, Changhua 51003, Taiwan, R.O.C, minchie.chiu@msa.hinet.net

Chang Ying-Chun

Department of Mechanical Engineering, Tatung University, Taipei, Taiwan, R.O.C.

Follow this and additional works at: https://jmstt.ntou.edu.tw/journal

Part of the Electrical and Computer Engineering Commons

\section{Recommended Citation}

Min-Chie, Chiu and Ying-Chun, Chang (2010) "NUMERICAL ASSESSMENT OF A SPACE-CONSTRAINED VENTING

SYSTEM WITH MULTI-CHAMBER PLUG MUFFLERS BY GA METHOD," Journal of Marine Science and Technology. Vol.

18: Iss. 3, Article 1.

DOI: $10.51400 / 2709-6998.1877$

Available at: https://jmstt.ntou.edu.tw/journal/vol18/iss3/1

This Research Article is brought to you for free and open access by Journal of Marine Science and Technology. It has been accepted for inclusion in Journal of Marine Science and Technology by an authorized editor of Journal of Marine Science and Technology. 
NUMERICAL ASSESSMENT OF A SPACE-CONSTRAINED VENTING SYSTEM WITH MULTI-CHAMBER PLUG MUFFLERS BY GA METHOD

Acknowledgements

The authors acknowledges the financial support of the National Science Council (NSC

97-2221-E-235-001, ROC) 


\title{
NUMERICAL ASSESSMENT OF A SPACE-CONSTRAINED VENTING SYSTEM WITH MULTI-CHAMBER PLUG MUFFLERS BY GA METHOD
}

\author{
Min-Chie Chiu* and Ying-Chun Chang**
}

Key words: multi-chamber plug muffler, four-pole transfer matrix method, back pressure, GA method.

\begin{abstract}
Recently, research on new techniques of single-chamber plug silencers has been addressed. However, the assessment of a multi-chamber plug muffler's optimal shape design within a constrained space as well as a pressure-drop limit which are mostly concerned with the necessity of operation and system venting in practical engineering work was rarely tackled. Therefore, this paper will not only analyze the sound transmission loss $(S T L)$ of a space-constrained multi-chamber plug muffler but also optimize the best design shape under a specified pressure drop.

In this paper, the generalized decoupling technique and plane wave theory used to solve the coupled acoustical problem of plug mufflers with perforated tubes are presented. The four-pole system matrix used to evaluate acoustic performance is also introduced in conjunction with a genetic algorithm (GA). Before the GA operation can be carried out, the accuracy of the mathematical model for a one-chamber plug muffler is checked using Munjal's experimental data.

To appreciate the sensitivity of a muffler's geometric parameters, the influence of sound transmission loss and related pressure drop with respect to design parameters is investigated. Furthermore, the noise reductions with respect to broadband exhaust noise emitted from a blower's inlet is also introduced and assessed. The optimal result in eliminating broadband noise reveals that the overall noise reductions with respect to various mufflers under a maximal allowable pressure drop of $800(\mathrm{~Pa})$ can achieve 40, 83 and $124 \mathrm{~dB}$. Consequently, the
\end{abstract}

Paper submitted 03/06/09; revised 06/06/09; accepted 06/08/09. Author for correspondence: Min-Chie Chiu (e-mail: minchie.chiu@msa.hinet.net).

*Department of Automatic Control Engineering, Chungchou Institute of Technology 6, Lane 2, Sec. 3, Shanchiao Rd., Yuanlin, Changhua 51003, Taiwan, R.O.C.

**Department of Mechanical Engineering, Tatung University, Taipei, Taiwan, R.O.C. approach used for the optimal design of the multi-chamber plug mufflers under space and back pressure constrained conditions is indeed easy and quite effective.

\section{INTRODUCTION}

Because high noise levels cause psychological and physiological symptoms [1], the demand for low-noise levels of various products has become vital [9]. To overcome the low frequency noise emitted from a venting system, a reactive muffler is customarily used [10]. Moreover, because the constrained problem is mostly concerned with the necessity of operation and maintenance in practical engineering work, there is a growing need to optimize the acoustical performance within a confined space. In addition, in order to keep the volume-flow-rate steady in a venting system, the back pressure of mufflers within an allowable range is compulsory.

In the past decade, to increase acoustical performance, the assessment of new acoustical elements (internal perforated plug and non-plug tubes) was discussed by Sullivan and Crocker in 1978 [17]. Based on the coupled equations derived by Sullivan and Crocker, a series of theories and numerical techniques in decoupling the acoustical problems have been proposed [7, 15, 13, 18]. Concerning the flowing effect, Munjal [11] and Peat [14] published the generalized decoupling and numerical decoupling methods. Munjal et al. [12] investigated the acoustical effect and the system's back pressure with respect to several design parameters for perforated plug and cross-flow perforated mufflers without space constrained and back-pressure limited situation. However, the assessment of the muffler's optimal shape design within a constrained space and a back-pressure limit which are mostly concerned with the necessity of operation and system venting in practical engineering work was rarely tackled. In previous work, to solve the space-constraint problem, Yeh et al. [19, 20] and Chiu [4] developed the optimized shaped mufflers equipped with non-perforated ducts and by using numerical method. With the purpose of improving the acoustical performance, the shape optimizations of one-chamber mufflers in conjunction with perforated plug/non-plug and cross-flow tubes under 
space-constrained situation were assessed [2, 3, 5]. However, the control of the system's back pressure which may retard the gas venting so as to damage the system had not been addressed.

In order to promote the acoustical performance and overcome the drawback of a possible overload pressure drop in the mufflers, three kinds of multi-chamber mufflers (a onechamber, two-chamber, and a three-chamber plug muffler) equipped with plug perforated ducts under the fixed space volume and the specified allowable pressure drop is presented. To facilitate the numerical assessment, three different GA techniques (a tournament selection in elitism, a uniform crossover, and a randomized mutation) are adopted.

By adjusting the muffler's shape, increasing the chambers, and using the GA and numerical decoupling methods, the optimal acoustical performance of the mufflers with acceptable back pressure can be achieved.

\section{MATHEMATICAL MODELS}

In this paper, three kinds of multi-chamber plug mufflers (a one-chamber, two-chamber, and a three-chamber plug muffler) hybridized with perforated tubes were adopted for the noise abatement on the constrained blower room shown in Fig. 1. The outlines of these mufflers as noise-reduction devices are shown in Figs. 2(a), 2(b) and 2(c).

The acoustical fields with respect to various mufflers (a one-chamber, two-chamber, and a three-chamber plug muffler) are shown in Figs. 3(a), 3(b), and 3(c). As indicated in Figs. 2(a) and 3(a), the one-chamber plug muffler composed of four acoustical elements is identified with three categories of components - two straight ducts, one perforated expanded plug duct, and one perforated contracted plug duct. The related acoustic pressure $p$ and acoustic particle velocity $u$ within the muffler are represented by five nodes. As indicated in Figs. 2(b) and 3(b), the two-chamber plug muffler consisting of seven acoustical elements is also identified with three categories of components - three straight ducts, two perforated expanded plug ducts, and two perforated contracted plug ducts. The related acoustic pressure $p$ and acoustic particle velocity $u$ within the muffler are represented by eight nodes. Consequently, the three-chamber plug muffler shown in Figs. 2(c) and 3(c) is composed of ten acoustical elements and identified with three categories of components - four straight ducts, three perforated expanded plug ducts, and three perforated contracted plug ducts. Eleven nodes inside the acoustical elements represent the acoustical properties in the acoustical field with acoustic pressure $p$ and acoustic particle velocity $u$ at their due location. The detailed mathematical derivation of various muffler systems is presented below.

\section{A One-Chamber Plug Muffler}

As derived in the previous work [3], individual transfer matrixes with respect to straight ducts, expansion perforated ducts, and contracted perforated ducts are described as follows:

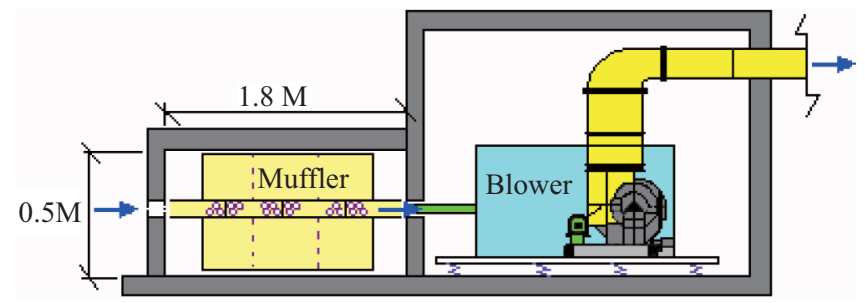

Fig. 1. A multi-chamber plug muffler within a constrained blower room.

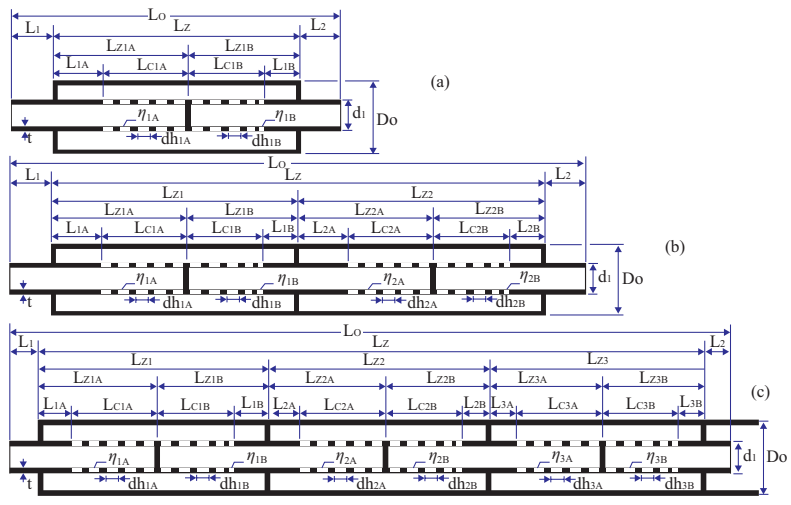

Fig. 2. The outlines of multi-chamber plug mufflers - (a) one-chamber, (b) two-chamber, and (c) three-chamber.

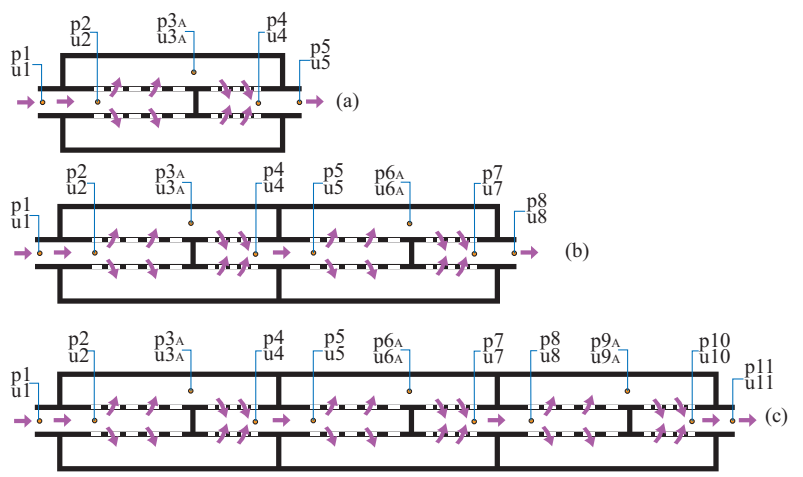

Fig. 3. The acoustical fields of multi-chamber plug mufflers (a) onechamber, (b) two-chamber, and (c) three-chamber.

$$
\begin{gathered}
\left(\begin{array}{c}
p_{1} \\
\rho_{o} c_{o} u_{1}
\end{array}\right)=e^{-j M_{1} k\left(L_{1}+L_{1 A}\right) /\left(1-M_{1}^{2}\right)}\left[\begin{array}{ll}
T S 1_{1,1} & T S 1_{1,2} \\
T S 1_{2,1} & T S 1_{2,2}
\end{array}\right]\left(\begin{array}{c}
p_{2} \\
\rho_{o} c_{o} u_{2}
\end{array}\right) \\
\left(\begin{array}{c}
p_{2} \\
\rho_{o} c_{o} u_{2}
\end{array}\right)=\left[\begin{array}{ll}
T P E 2_{1,1} & T P E 2_{1,2} \\
T P E 2_{2,1} & T P E 2_{2,2}
\end{array}\right]\left(\begin{array}{c}
p_{3 A} \\
\rho_{o} c_{o} u_{3 A}
\end{array}\right) \\
\left(\begin{array}{c}
p_{3 A} \\
\rho_{o} c_{o} u_{3 A}
\end{array}\right)=\left[\begin{array}{ll}
T P C 3_{1,1} & T P C 3_{1,2} \\
T P C 3_{2,1} & T P C 3_{2,2}
\end{array}\right]\left(\begin{array}{c}
p_{4} \\
\rho_{o} c_{o} u_{4}
\end{array}\right)
\end{gathered}
$$

$\left(\begin{array}{c}p_{4} \\ \rho_{o} c_{o} u_{4}\end{array}\right)=e^{-j M_{3} k\left(L_{2}+L_{1 B}\right) /\left(1-M_{3}^{2}\right)}\left[\begin{array}{cc}T S 4_{1,1} & T S 4_{1,2} \\ T S 4_{2,1} & T S 4_{2,2}\end{array}\right]\left(\begin{array}{c}p_{5} \\ \rho_{o} c_{o} u_{5}\end{array}\right)$ 
The total transfer matrix assembled by multiplication is

$$
\begin{aligned}
& \left(\begin{array}{c}
p_{1} \\
\rho_{o} c_{o} u_{1}
\end{array}\right) \\
& =e^{-j k\left[\frac{M_{1}\left(L_{1}+L_{1 A}\right)}{1-M_{1}^{2}}+\frac{M_{4}\left(L_{2}+L_{1 B}\right)}{1-M_{4}^{2}}\right]}\left[\begin{array}{ll}
T S 1_{1,1} & T S 1_{1,2} \\
T S 1_{2,1} & T S 1_{2,2}
\end{array}\right]\left[\begin{array}{ll}
T P E 2_{1,1} & T P E 2_{1,2} \\
T P E 2_{2,1} & T P E 2_{2,2}
\end{array}\right]
\end{aligned}
$$$$
\left[\begin{array}{ll}
T P C 3_{1,1} & T P C 3_{1,2} \\
T P C 3_{2,1} & T P C 3_{2,2}
\end{array}\right]\left[\begin{array}{ll}
T S 4_{1,1} & T S 4_{1,2} \\
T S 4_{2,1} & T S 4_{2,2}
\end{array}\right]\left(\begin{array}{c}
p_{5} \\
\rho_{o} c_{o} u_{5}
\end{array}\right)
$$

A simplified form in a matrix is expressed as

$$
\left(\begin{array}{c}
p_{1} \\
\rho_{o} c_{o} u_{1}
\end{array}\right)=\left[\begin{array}{cc}
T_{11}^{*} & T_{12}^{*} \\
T_{21}^{*} & T_{22}^{*}
\end{array}\right]\left(\begin{array}{c}
p_{5} \\
\rho_{o} c_{o} u_{5}
\end{array}\right)
$$

The sound transmission loss (STL) of a muffler is defined as [11]

$$
\begin{array}{r}
S T L_{1}\left(Q, f, A f f_{11}, A f f_{12}, A f f_{13}, A f f_{14}, A f f_{15}, \eta_{1}, d h_{1}\right) \\
=20 \log \left(\frac{\left|T_{11}^{*}+T_{12}^{*}+T_{21}^{*}+T_{22}^{*}\right|}{2}\right)+10 \log \left(\frac{S_{1}}{S_{4}}\right)
\end{array}
$$

where

$$
\begin{aligned}
& A f f_{11}=L_{\mathrm{Z}} / L_{\mathrm{o}} ; A f f_{12}=L_{\mathrm{Z} 1 \mathrm{~A}} / L_{\mathrm{Z}} ; A f f_{13}=L_{\mathrm{C} 1 \mathrm{~A}} / L_{\mathrm{Z} 1 \mathrm{~A}} ; \\
& A f f_{14}=L_{\mathrm{C} 1 \mathrm{~B}} / L_{\mathrm{Z} 1 \mathrm{~B}} ; A f f_{15}=d_{1} / D_{\mathrm{o}} ; L_{\mathrm{Z} 1 \mathrm{~B}}=L_{\mathrm{Z}}-L_{\mathrm{Z} 1 \mathrm{~A}} ; \\
& L_{1 \mathrm{~A}}=L_{\mathrm{Z} 1 \mathrm{~A}}-L_{\mathrm{C} 1 \mathrm{~A}} ; L_{1 \mathrm{~B}}=L_{\mathrm{Z} 1 \mathrm{~B}}-L_{\mathrm{C} 1 \mathrm{~B}} ; L_{1}=L_{2}=\left(L_{\mathrm{o}}-L_{\mathrm{Z}}\right) / 2
\end{aligned}
$$

The mean pressure drop $\left(\Delta p_{1}\right)$ of a one-chamber plug muffler investigated by Munjal et al. [12] is

$$
\begin{gathered}
\Delta p_{1}=\mathrm{H}_{1 *}\left(5.6 \mathrm{e}^{-0.23 \times 1}+67.3 \mathrm{e}^{-3.05 \times 1}\right) \\
\mathrm{H}_{1}=\rho V^{2} / 2 ; \mathrm{x} 1=4\left(L_{C 1 A}+L_{C 1 B}\right) \eta_{1} / d_{1}
\end{gathered}
$$

To meet the system requirement of allowable maximal pressure drop $\left(\Delta p_{a}\right)$, the mean pressure drop $\left(\Delta p_{1}\right)$ should be governed as

$$
\left(\Delta p_{a}\right) \geq \Delta p_{1}
$$

\section{A Two-Chamber Plug Muffler}

As indicated in Section III.1, the total transfer matrix assembled by multiplication is $\left(\begin{array}{c}p_{1} \\ \rho_{o} c_{o} u_{1}\end{array}\right)$

$=e^{-j k\left[\frac{M_{1}\left(L_{1}+L_{1 A}\right)}{1-M_{1}^{2}}+\frac{M_{4}\left(L_{2 A}+L_{1 B}\right)}{1-M_{4}^{2}}+\frac{M_{7}\left(L_{2}+L_{2 B}\right)}{1-M_{7}^{2}}\right]}\left[\begin{array}{ll}T S 1_{1,1} & T S 1_{1,2} \\ T S 1_{2,1} & T S 1_{2,2}\end{array}\right]$

$\left[\begin{array}{ll}T P E 2_{1,1} & T P E 2_{1,2} \\ T P E 2_{2,1} & T P E 2_{2,2}\end{array}\right]\left[\begin{array}{ll}T P C 3_{1,1} & T P C 3_{1,2} \\ T P C 3_{2,1} & T P C 3_{2,2}\end{array}\right]\left[\begin{array}{ll}T S 4_{1,1} & T S 4_{1,2} \\ T S 4_{2,1} & T S 4_{2,2}\end{array}\right]$

$\left[\begin{array}{ll}T P E 5_{1,1} & \text { TPE5 }_{1,2} \\ \text { TPE5 }_{2,1} & \text { TPE5 }_{2,2}\end{array}\right]\left[\begin{array}{ll}T P C 6_{1,1} & T P C 6_{1,2} \\ T P C 6_{2,1} & T P C 6_{2,2}\end{array}\right]\left[\begin{array}{ll}T S 7_{1,1} & T S 7_{1,2} \\ T S 7_{2,1} & T S 7_{2,2}\end{array}\right]$

$\left(\begin{array}{c}p_{7} \\ \rho_{o} c_{o} u_{7}\end{array}\right)$

The sound transmission loss $(S T L)$ is

$S_{T L}\left(Q, f, A f f_{21}, A f f_{22}, A f f_{23}, A f f_{24}, A f f_{25}, A f f_{26}, A f f_{27}, A f f_{28}\right.$,

$\left.A f f_{29}, \eta_{1}, d h_{1}\right)$

$=20 \log \left(\frac{\left|T_{11}^{*}+T_{12}^{*}+T_{21}^{*}+T_{22}^{*}\right|}{2}\right)+10 \log \left(\frac{S_{1}}{S_{7}}\right)$

where

$A f f_{21}=L_{\mathrm{Z}} / L_{\mathrm{o}} ; A f f_{22}=L_{\mathrm{Z1}} / L_{\mathrm{Z}} ; A f f_{23}=L_{\mathrm{Z} 1 \mathrm{~A}} / L_{\mathrm{Z} 1} ;$

$A f f_{24}=L_{\mathrm{Z} 2 \mathrm{~A}} / L_{\mathrm{Z} 2} ; A f f_{25}=L_{\mathrm{C} 1 \mathrm{~A}} / L_{\mathrm{Z} 1 \mathrm{~A}} ; A f f_{26}=L_{\mathrm{C} 1 \mathrm{~B}} / L_{\mathrm{Z} 1 \mathrm{~B}} ;$

$A f f_{27}=L_{\mathrm{C} 2 \mathrm{~A}} / L_{\mathrm{Z} 2 \mathrm{~A}} ; A f f_{28}=L_{\mathrm{C} 2 \mathrm{~B}} / L_{\mathrm{Z} 2 \mathrm{~B}} ; A f f_{29}=d_{1} / D_{0} ;$

$L_{\mathrm{Z} 2}=L_{\mathrm{Z}}-L_{\mathrm{Z} 1} ; L_{\mathrm{Z} 1 \mathrm{~B}}=L_{\mathrm{Z} 1}-L_{\mathrm{Z} 1 \mathrm{~A}} ; L_{1 \mathrm{~A}}=L_{\mathrm{Z} 1 \mathrm{~A}}-L_{\mathrm{C} 1 \mathrm{~A}} ;$

$L_{1 \mathrm{~B}}=L_{\mathrm{Z} 1 \mathrm{~B}}-L_{\mathrm{C} 1 \mathrm{~B}} ; L_{2 \mathrm{~A}}=L_{\mathrm{Z} 2 \mathrm{~A}}-L_{\mathrm{C} 2 \mathrm{~A}} ; L_{2 \mathrm{~B}}=L_{\mathrm{Z} 2 \mathrm{~B}}-L_{\mathrm{C} 2 \mathrm{~B}} ;$

$L_{1}=L_{2}=\left(L_{\mathrm{o}}-L_{\mathrm{Z}}\right) / 2$

The mean pressure drop $\left(\Delta p_{2}\right)$ of a two-chamber plug muffler is

$\Delta p_{2}=\mathrm{H}_{2 *}\left[\left(5.6 \mathrm{e}^{-0.23 \times 1}+67.3 \mathrm{e}^{-3.05 \times 1}\right)+\left(5.6 \mathrm{e}^{-0.23 \times 2}+67.3 \mathrm{e}^{-3.05 \times 2}\right)\right]$

$$
\mathrm{H}_{2}=\rho V^{2} / 2 \text {; }
$$$$
\mathrm{x}_{1}=4\left(L_{C 1 A}+L_{C 1 B}\right) \eta_{1} / D_{1} ; \mathrm{x}_{2}=4\left(L_{C 2 A}+L_{C 2 B}\right) \eta_{1} / d_{1}
$$

Similarly, the mean pressure drop $\left(\Delta p_{2}\right)$ is governed as

$$
\left(\Delta p_{a}\right) \geq \Delta p_{2}
$$




\section{A Three-Chamber Plug Muffler}

Similarly, the total transfer matrix assembled by multiplication is

$$
\begin{aligned}
& \left(\begin{array}{c}
p_{1} \\
\rho_{o} c_{o} u_{1}
\end{array}\right) \\
& =e^{-j k\left[\frac{M_{1}\left(L_{1}+L_{1 A}\right)}{1-M_{1}^{2}}+\frac{M_{4}\left(L_{2 A}+L_{1 B}\right)}{1-M_{4}^{2}}+\frac{M_{7}\left(L_{3 A}+L_{2 B}\right)}{1-M_{7}^{2}}+\frac{M_{10}\left(L_{2}+L_{3 B}\right)}{1-M_{10}^{2}}\right]}\left[\begin{array}{cc}
T S 1_{1,1} & T S 1_{1,2} \\
T S 1_{2,1} & T S 1_{2,2}
\end{array}\right]
\end{aligned}
$$$$
\left[\begin{array}{ll}
T P E 2_{1,1} & T P E 2_{1,2} \\
T P E 2_{2,1} & T P E 2_{2,2}
\end{array}\right]\left[\begin{array}{ll}
T P C 3_{1,1} & T P C 3_{1,2} \\
T P C 3_{2,1} & T P C 3_{2,2}
\end{array}\right]\left[\begin{array}{ll}
T S 4_{1,1} & T S 4_{1,2} \\
T S 4_{2,1} & T S 4_{2,2}
\end{array}\right]
$$$$
\left[\begin{array}{ll}
T P E 5_{1,1} & T^{2} E 5_{1,2} \\
T_{P E 5_{2,1}} & T_{P E 5_{2,2}}
\end{array}\right]\left[\begin{array}{ll}
T P C 6_{1,1} & T P C 6_{1,2} \\
T P C 6_{2,1} & T P C 6_{2,2}
\end{array}\right]\left[\begin{array}{ll}
T S 7_{1,1} & T S 7_{1,2} \\
T S 7_{2,1} & T S 7_{2,2}
\end{array}\right]
$$$$
\left[\begin{array}{ll}
T P E 8_{1,1} & T P E 8_{1,2} \\
T P E 8_{2,1} & T P E 8_{2,2}
\end{array}\right]\left[\begin{array}{ll}
T P C 9_{1,1} & T P C 9_{1,2} \\
T P C 9_{2,1} & T P C 9_{2,2}
\end{array}\right]\left[\begin{array}{ll}
T S 10_{1,1} & T S 10_{1,2} \\
T S 10_{2,1} & T S 10_{2,2}
\end{array}\right]
$$$$
\left(\begin{array}{c}
p_{11} \\
\rho_{o} c_{o} u_{11}
\end{array}\right)
$$

Likewise, the related sound transmission loss $(S T L)$ is

$$
\begin{gathered}
S_{L_{3}}\left(\begin{array}{l}
Q, f, A f f_{31}, A f f_{32}, A f f_{33}, A f f_{34}, A f f_{35}, A f f_{36}, \\
A f f_{37}, A f f_{38}, A f f_{39}, A f f_{40}, A f f_{41}, A f f_{42}, \eta_{1}, d h_{1}
\end{array}\right) \\
=20 \log \left(\frac{\left|T_{11}^{*}+T_{12}^{*}+T_{21}^{*}+T_{22}^{*}\right|}{2}\right)+10 \log \left(\frac{S_{1}}{S_{10}}\right)
\end{gathered}
$$

where

$A f f_{31}=L_{Z} / L_{0} ; A f f_{32}=L_{Z 2} / L_{Z} ; A f f_{33}=L_{Z 1 A} / L_{Z 1} ;$

$A f f_{34}=L_{\mathrm{Z} 2 \mathrm{~A}} / \mathrm{L}_{\mathrm{Z} 2} ; A f f_{35}=L_{\mathrm{Z} 3 \mathrm{~A}} / \mathrm{L}_{\mathrm{Z} 3} ; A f f_{36}=L_{\mathrm{C} 1 \mathrm{~A}} / \mathrm{L}_{\mathrm{Z} 1 \mathrm{~A}} ;$

$A f f_{37}=L_{\mathrm{C} 1 \mathrm{~B}} / \mathrm{L}_{\mathrm{Z} 1 \mathrm{~B}} ; A f f_{38}=L_{\mathrm{C} 2 \mathrm{~A}} / \mathrm{L}_{\mathrm{Z} 2 \mathrm{~A}} ; A f f_{39}=L_{\mathrm{C} 2 \mathrm{~B}} / \mathrm{L}_{\mathrm{Z} 2 \mathrm{~B}} ;$

$A f f_{40}=L_{\mathrm{C} 3 \mathrm{~A}} / \mathrm{L}_{\mathrm{Z} 3 \mathrm{~A}} ; A f f_{41}=L_{\mathrm{C} 3 \mathrm{~B}} / \mathrm{L}_{\mathrm{Z} 3 \mathrm{~B}} ; A f f_{42}=d_{1} / D_{0} ;$

$L_{\mathrm{Z} 1}=L_{\mathrm{Z} 3}=\left(L_{\mathrm{Z}}-L_{\mathrm{Z} 2}\right) / 2 ; L_{\mathrm{Z} 1 \mathrm{~B}}=L_{\mathrm{Z} 1}-L_{\mathrm{Z} 1 \mathrm{~A}} ; L_{1 \mathrm{~A}}=L_{\mathrm{Z} 1 \mathrm{~A}}-L_{\mathrm{C} 1 \mathrm{~A}} ;$

$L_{1 \mathrm{~B}}=L_{\mathrm{Z} 1 \mathrm{~B}}-L_{\mathrm{C} 1 \mathrm{~B}} ; L_{2 \mathrm{~A}}=L_{\mathrm{Z} 2 \mathrm{~A}}-L_{\mathrm{C} 2 \mathrm{~A}} ; L_{2 \mathrm{~B}}=L_{\mathrm{Z} 2 \mathrm{~B}}-L_{\mathrm{C} 2 \mathrm{~B}} ;$

$L_{3 \mathrm{~A}}=L_{\mathrm{Z} 3 \mathrm{~A}}-L_{\mathrm{C} 3 \mathrm{~A}} ; L_{3 \mathrm{~B}}=L_{\mathrm{Z} 3 \mathrm{~B}}-L_{\mathrm{C} 3 \mathrm{~B}} ; L_{1}=L_{2}=\left(L_{\mathrm{o}}-L_{\mathrm{Z}}\right) / 2$

The mean pressure drop $\left(\Delta p_{3}\right)$ of a three-chamber plug muffler is

$$
\begin{aligned}
\Delta p_{3}= & \mathrm{H}_{3 *}\left[\left(5.6 \mathrm{e}^{-0.23 \times 1}+67.3 \mathrm{e}^{-3.05 \times 1}\right)+\left(5.6 \mathrm{e}^{-0.23 \times 2}+67.3 \mathrm{e}^{-3.05 \times 2}\right)\right. \\
& \left.+\left(5.6 \mathrm{e}^{-0.23 \times 3}+67.3 \mathrm{e}^{-3.05 \times 3}\right)\right] \\
\mathrm{H}_{3}= & \rho V^{2} / 2 ; \mathrm{x}_{1}=4\left(L_{C 1 A}+L_{C 1 B}\right) \eta_{1} / D_{1} \\
\mathrm{x}_{2}= & 4\left(L_{C 2 A}+L_{C 2 B}\right) \eta_{1} / d_{1} ; \mathrm{x}_{3}=4\left(L_{C 3 A}+L_{C 3 B}\right) \eta_{1} / d_{1}
\end{aligned}
$$

Also, the mean pressure drop $\left(\Delta p_{3}\right)$ is governed as

$$
\left(\Delta p_{a}\right) \geq \Delta p_{3}
$$

\section{Overall Sound Power Level}

The silenced octave sound power level emitted from a silencer's outlet is

$$
S W L_{i}=S W L O_{i}-S T L_{i}
$$

where

(1) The $S W L O_{i}$ is the original $S W L$ at the inlet of a muffler (or pipe outlet), and $i$ is the index of the octave band frequency.

(2) The $S T L_{i}$ is the muffler's $S T L$ with respect to the relative octave band frequency.

(3) The $S W L_{i}$ is the silenced $S W L$ at the outlet of a muffler with respect to the relative octave band frequency.

Finally, the overall $S W L_{\mathrm{T}}$ silenced by a muffler at the outlet is

$$
S W L_{T}=10 * \log \left\{\sum_{i=1}^{8} 10^{S W L_{i} / 10}\right\}
$$$$
=10 * \log \left\{\begin{array}{ccc}
{[S W L O(f=63)-} & {[S W L O(f=125)-} & {[S W L O(f=250)-} \\
10^{S T L(f=63)] / 10}+10^{S T L(f=125)] / 10} & +10^{S T L(f=250)] / 10} \\
{[S W L O(f=500)-} & S W L O(f=1000)- & S W L O(f=2000)- \\
+10^{S T L(f=500)] / 10} & S 0^{S T L(f=1000)] / 10}+10^{S T L(f=2000)] / 10} \\
{[S W L O(f=4000)-} & \\
+10^{S T L(f=4000)] / 10} &
\end{array}\right\}
$$

\section{Objective Function}

By using the formulas of (7), (9), (11), (13), (15), (17), and (19), the objective function used in the GA optimization with respect to each type of plug muffler was established.

For a single-chamber plug muffler, the objective function in maximizing the STL at a pure tone $(f)$ is

$$
O B J_{11}=\operatorname{STL}_{1}\left(Q, f, A f f_{11}, A f f_{12}, A f f_{13}, A f f_{14}, A f f_{15}, \eta_{1}, d h_{1}, \Delta p_{1}\right)
$$

$$
=20 \log \left(\frac{\left|T_{11}^{*}+T_{12}^{*}+T_{21}^{*}+T_{22}^{*}\right|}{2}\right)+10 \log \left(\frac{S_{1}}{S_{4}}\right)
$$


To minimize the overall SWL, the objective function is

$$
\begin{aligned}
O B J_{12} & =S W L_{T}\left(Q, A f f_{11}, A f f_{12}, A f f_{13}, A f f_{14}, A f f_{15}, \eta_{1}, d h_{1}, \Delta p_{1}\right) \\
& =20 \log \left(\frac{\left|T_{11}^{*}+T_{12}^{*}+T_{21}^{*}+T_{22}^{*}\right|}{2}\right)+10 \log \left(\frac{S_{1}}{S_{4}}\right)
\end{aligned}
$$

Similarly, for a double-chamber plug muffler, the objective function in maximizing the STL at a pure tone $(f)$ is

$$
\begin{aligned}
O B J_{21} & =S T L_{2}\left(\begin{array}{l}
Q, f, A f f_{21}, A f f_{22}, A f f_{23}, A f f_{24}, A f f_{25}, A f f_{26}, \\
A f f_{27}, A f f_{28}, A f f_{29}, \eta_{1}, d h_{1}, \Delta p_{2}
\end{array}\right) \\
& =20 \log \left(\frac{\left|T_{11}^{*}+T_{12}^{*}+T_{21}^{*}+T_{22}^{*}\right|}{2}\right)+10 \log \left(\frac{S_{1}}{S_{7}}\right)
\end{aligned}
$$

Likewise, the minimized objective function with respect to the SWL in a double-chamber plug muffler is

$$
\begin{aligned}
O B J_{22} & =S W L_{T}\left(\begin{array}{l}
Q, A f f_{21}, A f f_{22}, A f f_{23}, A f f_{24}, A f f_{25}, A f f_{26}, \\
A f f_{27}, A f f_{28}, A f f_{29}, \eta_{1}, d h_{1}, \Delta p_{2}
\end{array}\right) \\
& =20 \log \left(\frac{\left|T_{11}^{*}+T_{12}^{*}+T_{21}^{*}+T_{22}^{*}\right|}{2}\right)+10 \log \left(\frac{S_{1}}{S_{7}}\right)
\end{aligned}
$$

Equally, for the three-chamber plug muffler, the objective function in maximizing the STL at a pure tone $(f)$ is

$$
\begin{aligned}
O B J_{31} & =\operatorname{STL}_{3}\left(\begin{array}{l}
Q, f, A_{31}, A f f_{32}, A f f_{33}, A f f_{34}, A f f_{35}, A f f_{36}, \\
A f f_{37}, A f f_{38}, A f f_{39}, A f f_{40}, A f f_{41}, A f f_{42}, \eta_{1}, d h_{1}, \Delta p_{3}
\end{array}\right) \\
& =20 \log \left(\frac{\left|T_{11}^{*}+T_{12}^{*}+T_{21}^{*}+T_{22}^{*}\right|}{2}\right)+10 \log \left(\frac{S_{1}}{S_{10}}\right)
\end{aligned}
$$

The related objective function in minimizing the overall SWL is

$$
\begin{aligned}
O B J_{32} & =S T L_{3}\left(\begin{array}{l}
Q, A f f_{31}, A f f_{32}, A f f_{33}, A f f_{34}, A f f_{35}, A f f_{36}, A f f_{37}, \\
A f f_{38}, A f f_{39}, A f f_{40}, A f f_{41}, A f f_{42}, \eta_{1}, d h_{1}, \Delta p_{3}
\end{array}\right) \\
& =20 \log \left(\frac{\left|T_{11}^{*}+T_{12}^{*}+T_{21}^{*}+T_{22}^{*}\right|}{2}\right)+10 \log \left(\frac{S_{1}}{S_{10}}\right)
\end{aligned}
$$

\section{MODEL CHECKS}

Before performing the $G A$ optimal simulation on mufflers,
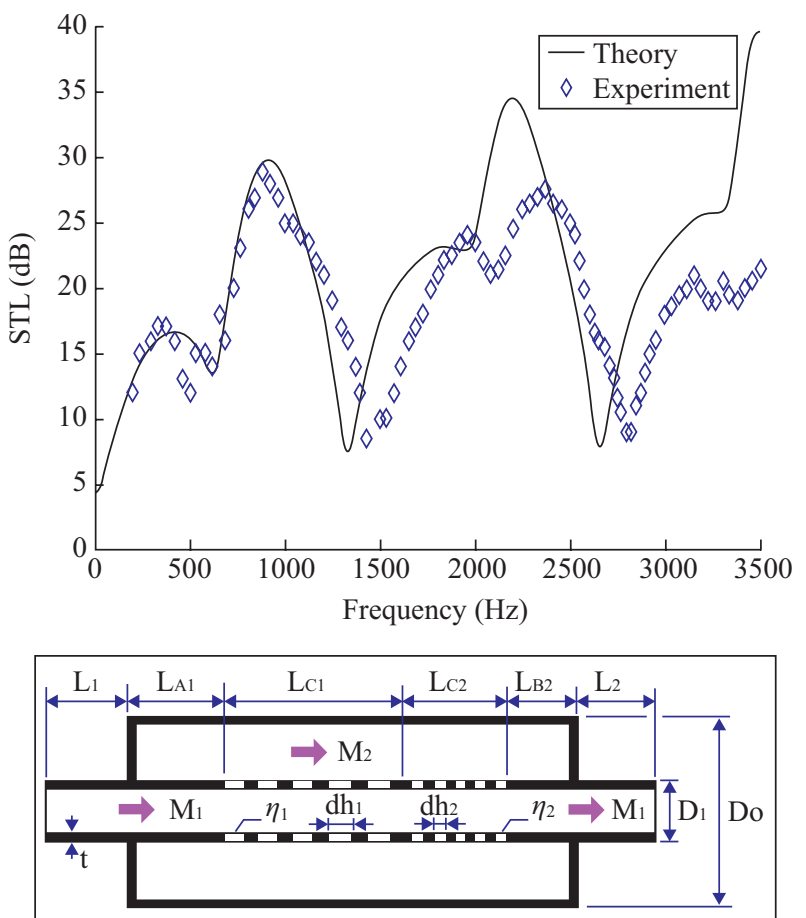

Fig. 4. Performance of a one-chamber perforated plug muffler with the mean flow $\left[M_{1}=M_{2}=0.05, D_{1}=0.0493(\mathrm{~m}), D 0=0.1016(\mathrm{~m}), L_{C l}=\right.$ $L_{C 2}=0.1286(\mathrm{~m}), L_{1}=L_{2}=0.1(\mathrm{~m}), . L_{\mathrm{A} 1}=L_{\mathrm{B} 2}=0.0(\mathrm{~m}), \mathrm{t}=0.081$ $\left.(\mathrm{m}), \mathrm{dh}_{1}=\mathrm{dh}_{2}=0.00249(\mathrm{~m}), \eta_{1}=\eta_{2}=0.037\right]$ [Experiment data is from Sullivan[13, 15, 19]].

accuracy checks of the mathematical models on a single-chamber plug perforated muffler are performed using the experimental data from Sullivan $[13,15,16]$. As depicted in Fig. 4, the performance curves with respective to theoretical and experiment data are relatively accurate and in agreement. Based on plane wave theory, the proposed theoretical cutoff frequency of $f c_{1}\left(f_{c 1}=\frac{1.84 c_{o}}{\pi D}\left(1-M^{2}\right)^{1 / 2}\right)$ is $1974 \mathrm{~Hz}$. Therefore, the proposed fundamental mathematical models with related acoustical components are acceptable. Consequently, the models linked with the numerical method are applied to the shape optimization in the following section.

\section{CASE STUDIES}

In this paper, a blower confined within a RC (reinforced concrete) room is shown in Fig. 1. The noise level in the equipment venting outlet is remarkable. To efficiently depress the noise, the multi-chamber plug muffler hybridized with perforated tubes is considered. The spectrum of the exhaust sound power level $(S W L)$ at the muffler inlet is

\begin{tabular}{|c|c|c|c|c|c|c|c|}
\hline $\mathrm{f}(\mathrm{Hz})$ & 125 & 250 & 500 & $1 \mathrm{k}$ & $2 \mathrm{k}$ & $4 \mathrm{k}$ & Overall SWL \\
\hline SWL (dB) & 128 & 135 & 126 & 115 & 108 & 100 & 136.3 \\
\hline
\end{tabular}


Table 1. Range of design parameters for three kinds of multi-chamber plug mufflers.

\begin{tabular}{|c|c|}
\hline Muffler Type & Range of design parameters \\
\hline One-Chamber & $\begin{array}{l}\text { Targeted f: }\{250,550,750\} ; \mathrm{Q}=0.01\left(\mathrm{~m}^{3} / \mathrm{s}\right) ; \mathrm{D}_{\mathrm{o}}=0.5(\mathrm{~m}) ; \mathrm{Lo}=1.8(\mathrm{~m}) ; \\
A f f_{11}:[0.5,0.9] ; A f f_{12}:[0.3,0.7] ; A f f_{13}:[0.5,0.9] ; A f f_{14}:[0.5,0.9] ; A f f_{15}:[0.5,0.6] ; \eta_{1}:[0.03,0.1] ; \mathrm{dh}_{1}:[0.00175,0.007] ; \Delta \mathrm{p}_{\mathrm{a}}: \\
800(\mathrm{~Pa})\end{array}$ \\
\hline Two-Chamber & $\begin{array}{l}\text { Targeted f: }\{250,550,750\} ; \mathrm{Q}=0.01\left(\mathrm{~m}^{3} / \mathrm{s}\right) ; \mathrm{D}_{\mathrm{o}}=0.5(\mathrm{~m}) ; \mathrm{Lo}=1.8(\mathrm{~m}) ; \\
\text { Aff }_{21}:[0.5,0.9] ; A f f_{22}:[0.3,0.7] ; \text { Aff }_{23}:[0.3,0.7] ; \text { Aff }_{24}:[0.3,0.7] ; \text { Aff }_{25}:[0.5,0.9] ; \text { Aff }_{26}:[0.5,0.9] ; \text { Aff }_{27}:[0.5,0.9] ; \text { Aff }_{28}:[0.5, \\
0.9] ; A f f_{29}:[0.5,0.6] ; \eta_{1}:[0.03,0.1] ; \mathrm{dh}_{1}:[0.00175,0.007] ; \Delta \mathrm{p}_{\mathrm{a}}: 800(\mathrm{~Pa})\end{array}$ \\
\hline Three-Chamber & $\begin{array}{l}\text { Targeted f: }\{250,550,750\} ; \mathrm{Q}=0.01\left(\mathrm{~m}^{3} / \mathrm{s}\right) ; \mathrm{D}_{\mathrm{o}}=0.5(\mathrm{~m}) ; \mathrm{Lo}=1.8(\mathrm{~m}) ; \\
\text { Aff }_{31}:[0.5,0.9] ; \text { Aff }_{32}:[0.3,0.7] ; \text { Aff }_{33}:[0.3,0.7] ; \text { Aff }_{34}:[0.3,0.7] ; \text { Aff }_{35}:[0.3,0.7] ; \text { Aff }_{36}:[0.5,0.9] ; \text { Aff }_{37}:[0.5,0.9] ; \text { Aff }_{38}:[0.5, \\
0.9] ; A f f_{39}:[0.5,0.6] ; \text { Aff }_{40}:[0.5,0.9] ; \text { Aff }_{41}:[0.5,0.9] ; \text { Aff }_{42}:[0.3,0.7] ; \eta_{1}:[0.03,0.1] ; \mathrm{dh}_{1}:[0.00175,0.007] ; \Delta \mathrm{p}_{\mathrm{a}}: 800(\mathrm{~Pa})\end{array}$ \\
\hline
\end{tabular}

Before the minimization of a broadband noise is performed, the maximization of the STL with respect to three kinds of perforated plug mufflers at various targeted pure tones $(250$, $550,750 \mathrm{~Hz}$ ) has been performed for the purpose of an accuracy check on the GA method. As shown in Fig. 1, the available space for a muffler is $0.5 \mathrm{~m}$ in width, $0.5 \mathrm{~m}$ in height, and $1.8 \mathrm{~m}$ in length. In the existing venting system, the flow rate $(Q)$ and thickness of the perforated tube $(t)$ are given as 0.01 $\left(\mathrm{m}^{3} / \mathrm{s}\right)$ and $0.0015(\mathrm{~m})$. To prevent overloading back pressure which will slow down the preset volume- flow-rate $(\mathrm{Q})$, the allowable maximal $\Delta p$ of $800(\mathrm{~Pa})$ in the muffler system is specified in advance. The corresponding space constraints and the ranges of the design parameters for each muffler are summarized in Table 1.

\section{GENETIC ALGORITHM}

The concept of Genetic Algorithms, first formalized by Holland [6] and then extended to functional optimization by Jong [8], involves the use of optimization search strategies patterned after the Darwinian notion of natural selection.

For the optimization of the objective function $(O B J)$, the design parameters of $\left(X_{1}, X_{2}, \ldots, X_{k}\right)$ were determined. When the bit (the bit length of the chromosome) was chosen, the interval of the design parameter $\left(X_{k}\right)$ with $[L b, U b]_{k}$ was then mapped to the band of the binary value. The mapping system between the variable interval of $[L b, U b]_{k}$ and the $k^{\text {th }}$ binary chromosome of

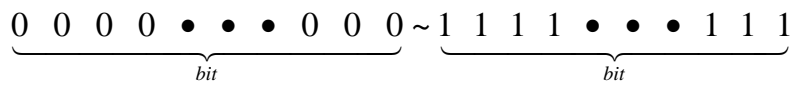

was then built. The encoding from $\mathrm{x}$ to $B 2 D$ (binary to decimal) can be performed as

$$
B 2 D_{k}=\text { integer }\left\{\frac{x_{k}-L b_{k}}{U b_{k}-L b_{k}}\left(2^{b i t}-1\right)\right\}
$$

The initial population was built up by randomization. The parameter set was encoded to form a string which represented the chromosome. By evaluating the objective function $(O B J)$,

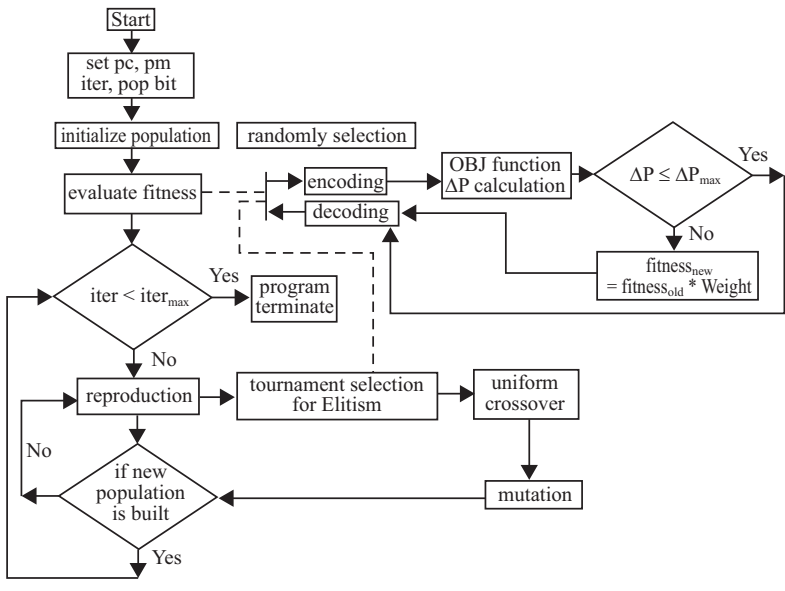

Fig. 5. The block diagram of the GA optimization on mufflers.

the whole set of chromosomes $\left[B 2 D_{1}, B 2 D_{2}, \ldots, B 2 D_{k}\right]$ that changed from binary form to decimal form was then assigned a fitness by decoding the transformation system.

$$
\text { fitness }=\operatorname{OBJ}\left(X_{1}, X_{2}, \ldots, X_{k}\right)
$$

where

$$
X_{k}=B 2 D_{k}^{*}\left(U b_{k}-L b_{k}\right) /\left(2^{\mathrm{bit}}-1\right)+L b_{k}
$$

As the block diagram indicates in Fig. 5, during the decoding process, the back pressure $(\Delta \mathrm{p})$ will be calculated and compared with the limit of $\Delta \mathrm{p}_{\mathrm{a}}$. If $\Delta \mathrm{p}$ is smaller than $\Delta \mathrm{p}_{\mathrm{a}}$, the current offspring will be valid and used for further evolution. If this is not the case, fitness will be weighted to discard the current gene.

As indicated in Fig. 6, to process the elitism of a gene, the tournament selection, a random comparison of the relative fitness from pairs of chromosomes, was applied. During the GA optimization, one pair of offspring from the selected parent was generated by uniform crossover with a probability of $p c$. Genetically, mutation occurred with a probability of $p m$ where the new and unexpected point was brought into the GA optimizer's search domain. To prevent the best gene from 


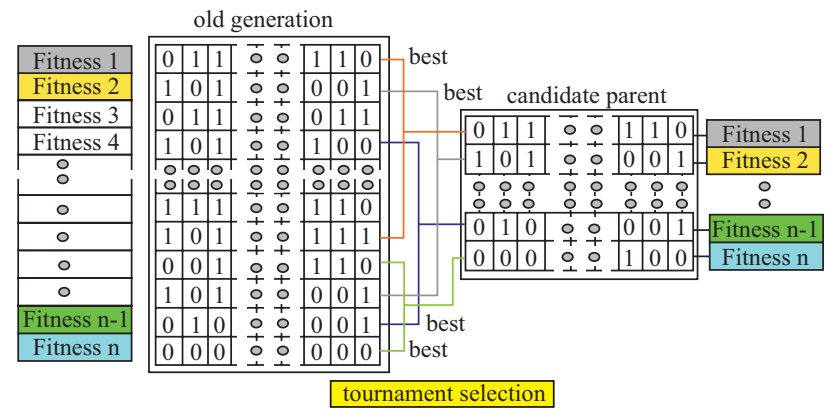

Fig. 6. Scheme of elitism by tournament selection.

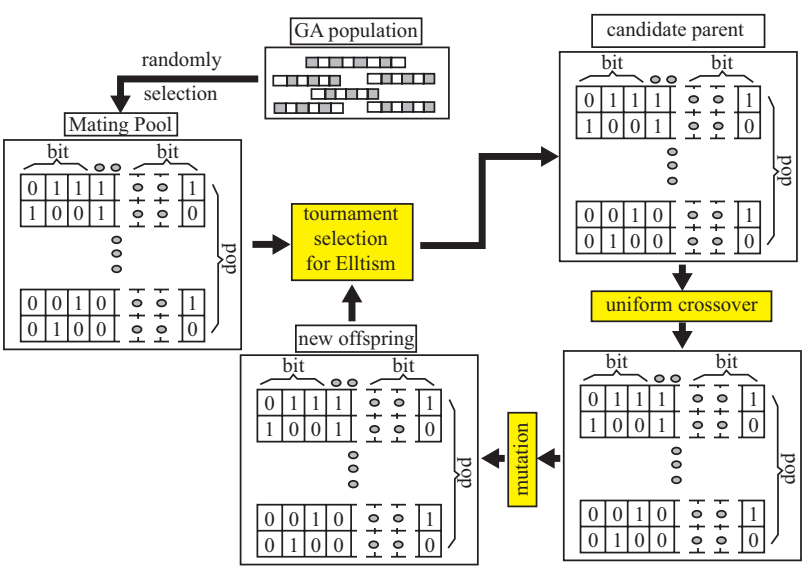

Fig. 7. Operations in the GA method.

disappearing and to improve the accuracy of optimization during reproduction, the elitism scheme of keeping the best gene (one pair) in the parent generation with the tournament strategy was developed.

The process was terminated when a number of generations exceeded a pre-selected value of genno. The operations in the GA method are pictured in Fig. 7.

To simplify the optimization for three kinds of plug mufflers, the flow rate $\left(Q=0.01\left(\mathrm{~m}^{3} / \mathrm{s}\right)\right)$ and thickness of the perforated tube $\left(\mathrm{t}_{1}=\mathrm{t}_{2}=0.0081(\mathrm{~m})\right)$ are preset in advance; therefore, Eqs. (20), (21), (22), the objective functions $\left(O B J_{11}\right.$, $O B J_{12}, O B J_{21}, O B J_{22}, O B J_{31}$, and $\left.O B J_{32}\right)$ and their ranges are reduced and set as

$$
\begin{aligned}
& \mathrm{OBJ}_{11}\left(X_{1}, X_{2}, X_{3}, X_{4}, X_{5}, X_{6}, X_{7}, X_{8}\right) \\
& =\operatorname{STL}\left(\operatorname{aff}_{11}, \text { aff }_{12}, \text { aff }_{13}, a f f_{14}, a f f_{15}, \eta_{1}, d h_{1}, \Delta p_{a}\right) \\
& \mathrm{OBJ}_{12}\left(X_{1}, X_{2}, X_{3}, X_{4}, X_{5}, X_{6}, X_{7}, X_{8}\right) \\
& =S W L_{T}\left(a f f_{11}, a f f_{12}, a f f_{13}, a f f_{14}, a f f_{15}, \eta_{1}, d h_{1}, \Delta p_{a}\right) \\
& O B J_{21}\left(X_{1}, X_{2}, X_{3}, X_{4}, X_{5}, X_{6}, X_{7}, X_{8}, X_{9}, X_{10}, X_{11}, X_{12}\right) \\
& =\operatorname{STL}\left(\text { aff }_{21}, \text { aff }_{22}, a f f_{23}, a f f_{24}, \text { aff }_{25}, \text { aff }_{26}, a f f_{27}, a f f_{28}\right. \text {, } \\
& \text { aff } \left._{29}, \eta_{1}, d h_{1}, \Delta p_{a}\right)
\end{aligned}
$$

$$
\begin{aligned}
O_{22} & \left.X_{1}, X_{2}, X_{3}, X_{4}, X_{5}, X_{6}, X_{7}, X_{8}, X_{9}, X_{10}, X_{11}, X_{12}\right) \\
= & S W L_{T}\left(a f f_{21}, a f f_{22}, a f f_{23}, a_{24}, a f f_{25}, a f f_{26}, a f f_{27}, a f f_{28},\right. \\
& \left.\quad \operatorname{aff}_{29}, \eta_{1}, d h_{1}, \Delta p_{a}\right)
\end{aligned}
$$

$\mathrm{OBJ}_{31}\left(X_{1}, X_{2}, X_{3}, X_{4}, X_{5}, X_{6}, X_{7}, X_{8}, X_{9}, X_{10}, X_{11}, X_{12}\right.$,

$$
\left.X_{13}, X_{14}, X_{15}\right)
$$$$
=\operatorname{STL}\left(\text { aff }_{31}, \text { aff }_{32}, \text { aff }_{33}, \text { aff }_{34}, a f f_{35}, \text { aff }_{36}, \text { aff }_{37}, a f f_{38}, a f f_{39}\right. \text {, }
$$$$
\left.a_{40}, a f f_{41}, a f f_{42}, \eta_{1}, d h_{1}, \Delta p_{a}\right)
$$

$$
\begin{aligned}
& O_{32}\left(X_{1}, X_{2}, X_{3}, X_{4}, X_{5}, X_{6}, X_{7}, X_{8}, X_{9}, X_{10}, X_{11}, X_{12},\right. \\
& \left.\quad X_{13}, X_{14}, X_{15}\right) \\
& =\operatorname{SWL}_{T}\left(\operatorname{aff}_{31}, \operatorname{aff}_{32}, \operatorname{aff}_{33}, \operatorname{aff}_{34}, \operatorname{aff}_{35}, \operatorname{aff}_{36}, \text { aff }_{37}, \text { aff }_{38}, \text { aff }_{39},\right. \\
& \left.\quad \operatorname{aff}_{40}, \text { aff }_{41}, \text { aff }_{42}, \eta_{1}, a h_{1}, \Delta p_{a}\right)
\end{aligned}
$$

\section{RESULTS AND DISCUSSION}

\section{Results}

To achieve good optimization, five kinds of optimal GA parameters, including population size ( $p o p)$, chromosome length (bit), maximum generation $\left(\right.$ iter $\left._{\max }\right)$, crossover ratio $(p c)$, and mutation ratio $(p m)$ are obtained by varying their values during optimization. The optimization system is encoded by Fortran and run on an IBM PC - Pentium IV. The results of two kinds of optimizations - one of the pure tone noise used for GA's accuracy check and the other of broadband noise occurring in a blower room - are described below.

\section{1) Pure Tone Noise Optimization}

\section{A. One-Chamber Plug Muffler}

For a one-chamber plug muffler, various sets of $G A$ parameters are tested during optimal process. The resultant simulated result optimized with respect to the pure tone of $250 \mathrm{~Hz}$ is shown in Table 2. As indicated in Table 2, the optimal design data can be obtained when the $G A$ parameters at pop, bit, iter $r_{\max }, p c$, and $p m=80,10,200,0.6,0.05$ are applied. Using this GA parameter set with two other pure tones (550, $750 \mathrm{~Hz}$ ), the muffler's optimal sizes with respect to various pure tones are summarized in Table 3 . Using the optimal design in a theoretical calculation, three optimal STL curves with respect to targeted frequencies are plotted and depicted in Fig. 8. As revealed in Fig. 8, the STLs are precisely maximized at the desired frequencies. The related mufflers' sizes with respect to three kinds of pure tones $(250,550,750 \mathrm{~Hz})$ are shown in Figs. 9-11.

To appreciate the influence of the STL and $\Delta \mathrm{p}$ with respect to other parameters, a simple sensitivity analysis using seven 
Table 2. Optimal STLs for a one-chamber plug perforated muffler (targeted frequency: $250 \mathrm{~Hz}$ ).

\begin{tabular}{|c|c|c|c|c|c|c|c|c|c|}
\hline \multicolumn{5}{|c|}{ Optimal GA parameters } & \multicolumn{5}{|c|}{ Optimal Result } \\
\hline \multirow{2}{*}{ pop } & \multirow{2}{*}{ bit } & \multirow{2}{*}{$p m$} & \multirow{2}{*}{$p c$} & \multirow{2}{*}{ iter $_{\max }$} & $A f f_{11}$ & Aff 12 & $A f f_{13}$ & $A f f_{14}$ & STL $(\mathrm{dB})$ \\
\hline & & & & & 0.9000 & 0.7000 & 0.5000 & 0.5000 & 71.299 \\
\hline \multirow{2}{*}{80} & \multirow{2}{*}{10} & \multirow{2}{*}{0.05} & \multirow{2}{*}{0.6} & \multirow{2}{*}{200} & $A f f_{15}$ & $\eta_{1}$ & $d h_{1}(\mathrm{~m})$ & & $\Delta \mathrm{p}(\mathrm{Pa})$ \\
\hline & & & & & 0.0500 & 0.1000 & 0.0070 & & 532.3 \\
\hline
\end{tabular}

Table 3. Optimal STLs for a one-chamber plug perforated muffler with respect to various targeted frequencies (with $\Delta p$ constraint).

\begin{tabular}{|c|c|c|c|c|c|c|}
\hline Item & Targeted frequency & & & Results & & \\
\hline \multirow{4}{*}{1} & \multirow{4}{*}{$250 \mathrm{~Hz}$} & $A f f_{11}$ & $A f f_{12}$ & $A f f_{13}$ & $A f f_{14}$ & STL $(\mathrm{dB})$ \\
\hline & & 0.9000 & 0.7000 & 0.5000 & 0.5000 & 71.299 \\
\hline & & $A f f_{15}$ & $\eta_{1}$ & $d h_{1}(\mathrm{~m})$ & & $\Delta \mathrm{p}(\mathrm{Pa})$ \\
\hline & & 0.0500 & 0.1000 & 0.0070 & & 532.3 \\
\hline \multirow{4}{*}{2} & \multirow{4}{*}{$550 \mathrm{~Hz}$} & $A f f_{11}$ & $A f f_{12}$ & Aff 13 & $A f f_{14}$ & STL $(\mathrm{dB})$ \\
\hline & & 0.7964 & 0.5194 & 0.6775 & 0.6517 & 91.857 \\
\hline & & $A f f_{15}$ & $\eta_{1}$ & $d h_{1}(\mathrm{~m})$ & & $\Delta \mathrm{p}(\mathrm{Pa})$ \\
\hline & & 0.0538 & 0.0999 & 0.0069 & & 340.5 \\
\hline \multirow{4}{*}{3} & \multirow{4}{*}{$750 \mathrm{~Hz}$} & $A f f_{11}$ & $A f f_{12}$ & $A f f_{13}$ & $A f f_{14}$ & STL $(\mathrm{dB})$ \\
\hline & & 0.8128 & 0.5174 & 0.7796 & 0.7639 & 93.536 \\
\hline & & $A f f_{15}$ & $\eta_{1}$ & $d h_{1}(\mathrm{~m})$ & & $\Delta \mathrm{p}(\mathrm{Pa})$ \\
\hline & & 0.0532 & 0.0995 & 0.0066 & & 251.0 \\
\hline
\end{tabular}

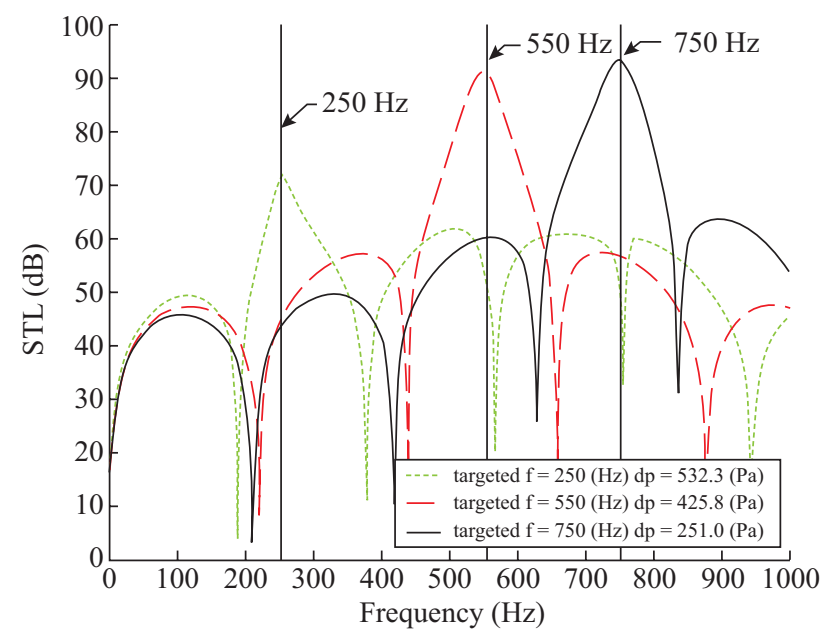

Fig. 8. Optimal STL with respect to frequencies for a one-chamber plug silencer [targeted frequency: 250,550 and $750 \mathrm{~Hz}$ ].

parameters (Aff $11, A f f_{12}, A f f_{13}, A f f_{14}, A f f_{15}, \eta_{1}$, and $\left.\mathrm{dh}_{1}\right)$ for a one-chamber plug muffler at a targeted frequency of $250(\mathrm{~Hz})$ is performed and shown in Figs. 12-18. As indicated in Figs. $12-18$, it is obvious that the STL is inversely proportional to the diameter of the inner duct $\left(A f f_{15}\right)$ and to the lengths of the perforated ducts $\left(A f f_{13}, A f f_{14}\right)$. Moreover, the back pressure $\Delta \mathrm{p}$ will obviously decrease when either the length of the chamber $\left(A f f_{11}\right)$, the lengths of the perforated ducts $\left(A f f_{13}, A f f_{14}\right)$, the

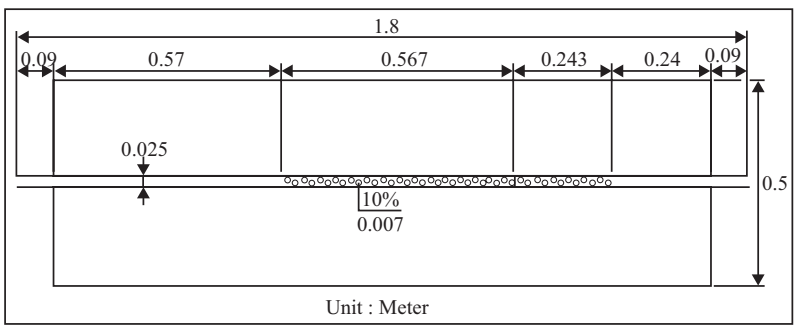

Fig. 9. Optimal shape of a one-chamber plug muffler with a targeted frequency of $250 \mathrm{~Hz}$.

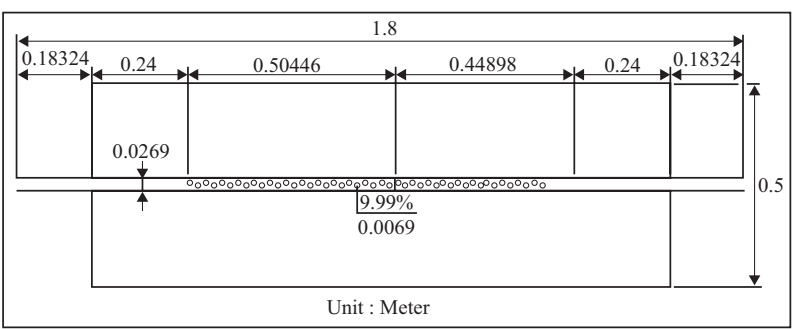

Fig. 10. Optimal shape of a one-chamber plug muffler with a targeted frequency of $550 \mathrm{~Hz}$.

diameter of the inner duct $\left(A f f_{15}\right)$, or the porosity of the inner duct $\left(\eta_{1}\right)$ is increased. Because the decrement of the parameters $\left(A f f_{13}, A f f_{14} A f f_{15}\right)$ will result in the increment of both the 


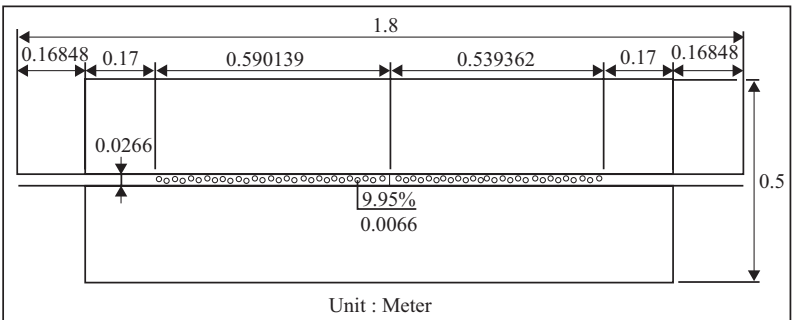

Fig. 11. Optimal shape of a one-chamber plug muffler with a targeted frequency of $750 \mathrm{~Hz}$.

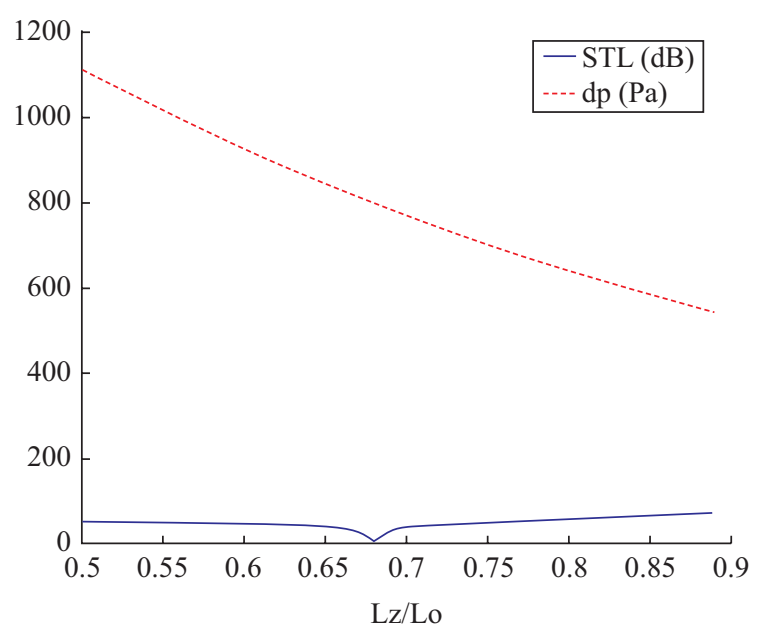

Fig. 12. Influence of $A f f_{11}(\mathrm{Lz} / \mathrm{Lo})$ on a STL and a $\Delta p$ with a targeted frequency of $250 \mathrm{~Hz}$.

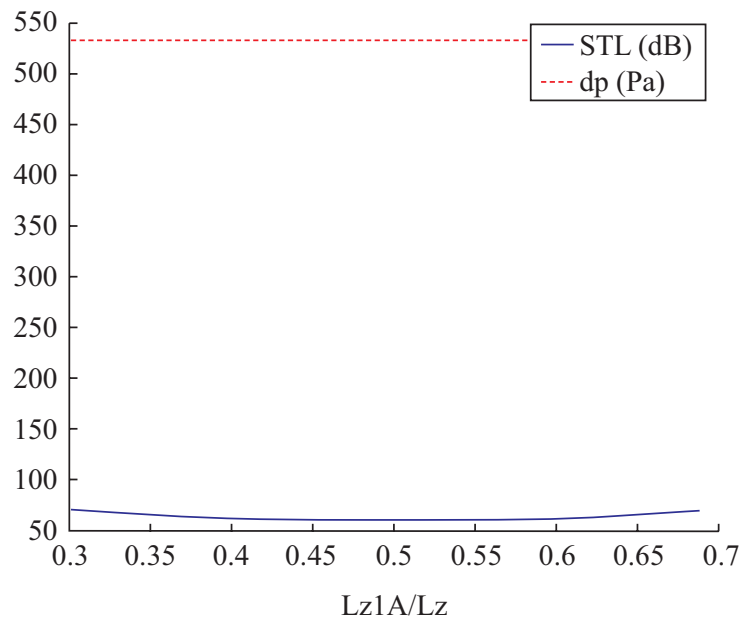

Fig. 13. Influence of $A f f_{12}(\operatorname{Lz} 1 \mathrm{~A} / \mathrm{Lz})$ on a STL and a $\Delta p$ with a targeted frequency of $250 \mathrm{~Hz}$.

STL and $\Delta \mathrm{p}$ simultaneously, a compromise between these parameters during the numerical optimization process will be required. Therefore, to reach a higher STL with a $\Delta \mathrm{p}$ below the allowable maximal pressure drop, an appropriate decrement of the $A f f_{13}, A f f_{14} A f f_{15}$ is essential. As indicated in Table

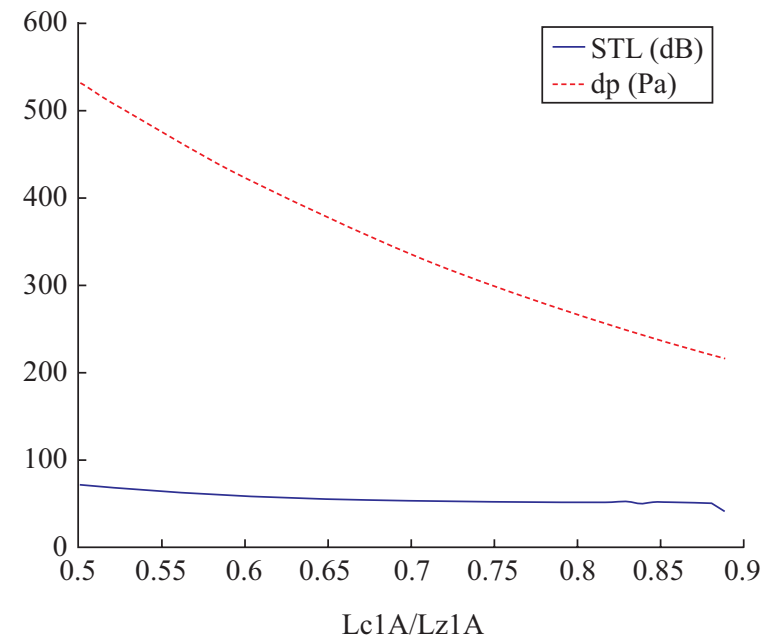

Fig. 14. Influence of $A f f_{13}(\operatorname{Lc1A} / \operatorname{Lz1A})$ on a STL and a $\Delta p$ with a targeted frequency of $250 \mathrm{~Hz}$.

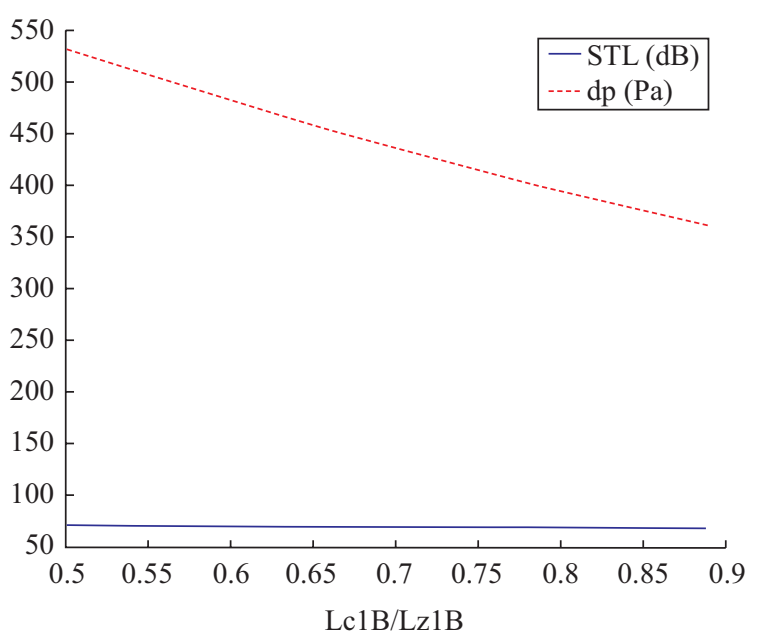

Fig. 15. Influence of $A f f_{14}(\mathrm{Lc} 1 \mathrm{~B} / \mathrm{Lz} 1 \mathrm{~B})$ on a $S T L$ and a $\Delta p$ with a targeted frequency of $250 \mathrm{~Hz}$.

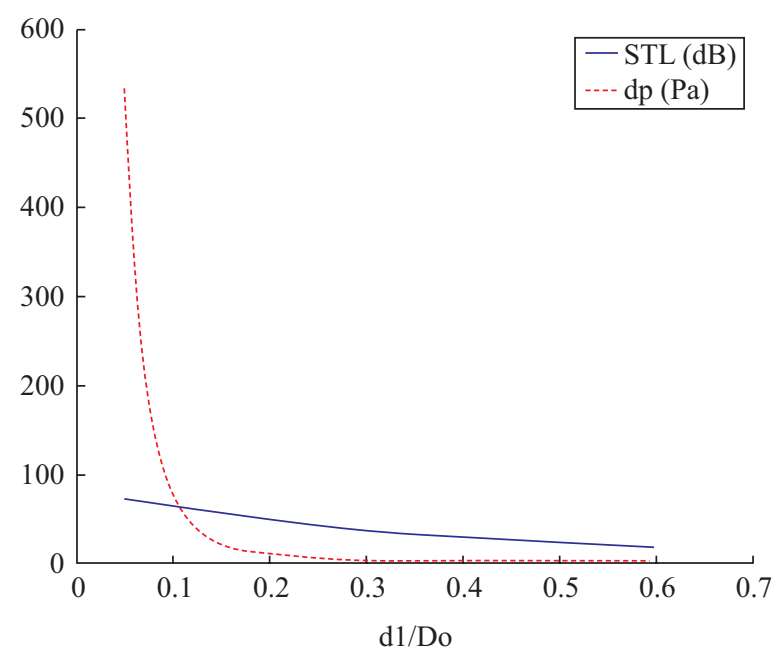

Fig. 16. Influence of $A f f_{15}(\mathrm{~d} 1 / \mathrm{Do})$ on a STL and a $\Delta \mathrm{p}$ with a targeted frequency of $250 \mathrm{~Hz}$. 
Table 4. Optimal STLs for a two-chamber plug perforated muffler (targeted frequency: $250 \mathrm{~Hz}$ ).

\begin{tabular}{|c|c|c|c|c|c|c|c|c|c|}
\hline \multicolumn{5}{|c|}{ Optimal GA parameters } & \multicolumn{5}{|c|}{ Optimal Result } \\
\hline \multirow{2}{*}{ pop } & \multirow{2}{*}{ bit } & \multirow{2}{*}{$p m$} & \multirow{2}{*}{$p c$} & \multirow{2}{*}{ iter $r_{\max }$} & $A f f_{21}$ & $A f f_{22}$ & $A f f_{23}$ & $A f f_{24}$ & $\mathrm{STL}(\mathrm{dB})$ \\
\hline & & & & & 0.5000 & 0.3000 & 0.7000 & 0.7000 & 104.1 \\
\hline \multirow{4}{*}{80} & \multirow{4}{*}{25} & \multirow{4}{*}{0.05} & \multirow{4}{*}{0.6} & \multirow{4}{*}{500} & $A f f_{25}$ & $A f f_{26}$ & $A f f_{27}$ & $A f f_{28}$ & $\Delta \mathrm{p}(\mathrm{Pa})$ \\
\hline & & & & & 0.5000 & 0.5000 & 0.5125 & 0.5000 & 800.0 \\
\hline & & & & & $A f f_{29}$ & $\eta_{1}$ & $d h_{1}(\mathrm{~m})$ & & \\
\hline & & & & & 0.1330 & 0.0300 & 0.0018 & & \\
\hline
\end{tabular}

Notes: $A f f_{21}=\mathrm{Lz} / \mathrm{Lo} ; A f f_{22}=\mathrm{Lz} 1 / \mathrm{Lz} ; A f f_{23}=\mathrm{Lz} 1 \mathrm{~A} / \mathrm{Lz} 1 ; A f f_{24}=\mathrm{Lz} 2 \mathrm{~A} / \mathrm{Lz} 2 ; A f f_{25}=\mathrm{Lc} 1 \mathrm{~A} / \mathrm{Lz} 1 \mathrm{~A} ; A f f_{26}=\mathrm{Lc} 1 \mathrm{~B} / \mathrm{Lz} 1 \mathrm{~B} ; A f f_{27}=\mathrm{Lc} 2 \mathrm{~A} / \mathrm{Lz} 2 \mathrm{~A}$; $A f f_{28}=\mathrm{Lc} 2 \mathrm{~B} / \mathrm{Lz} 2 \mathrm{~B} ; A_{29}=\mathrm{d} 1 / \mathrm{Do}$

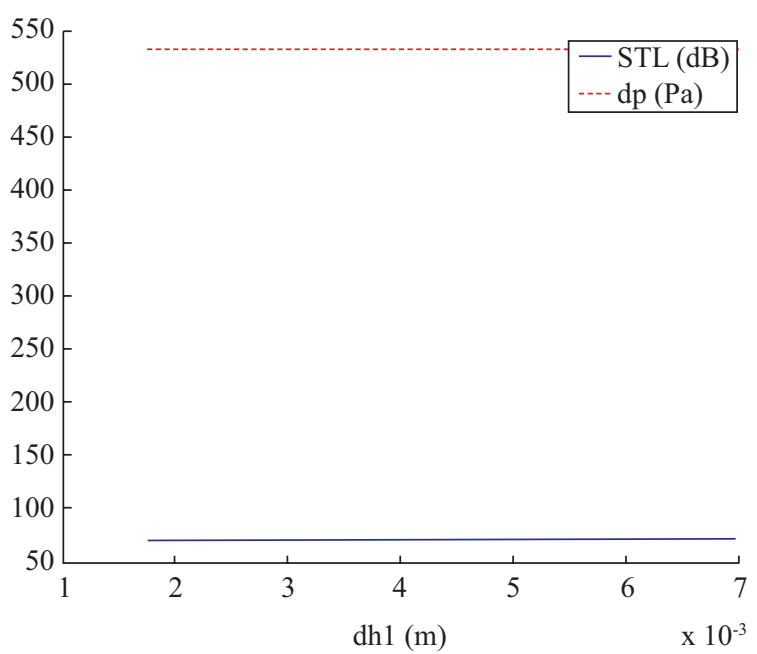

Fig. 17. Influence of dh1 on a STL and a $\Delta p$ with a targeted frequency of $250 \mathrm{~Hz}$.

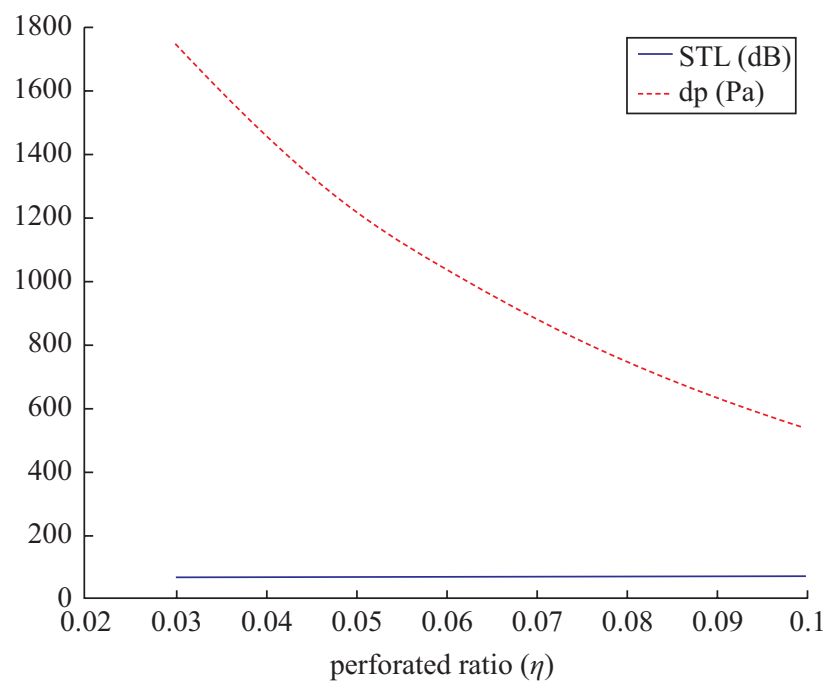

Fig. 18. Influence of $\eta$ on a STL and a $\Delta p$ with a targeted frequency of $250 \mathrm{~Hz}$.

3, the STL at a higher targeted frequency will be larger than that at a lower targeted frequency.

B. Two-Chamber Plug Muffler

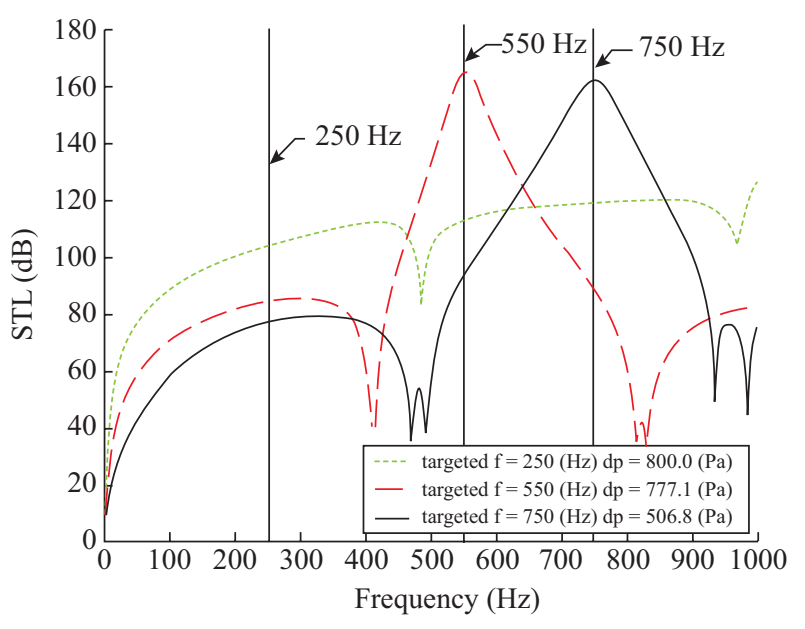

Fig. 19. Optimal STL with respect to frequencies for a two-chamber plug silencer [targeted frequency: 250,550 and $750 \mathrm{~Hz}$ ].

For a two-chamber plug muffler, thirteen sets of $G A$ parameters are tested by varying the values of the GA parameters. The optimized result with respect to the pure tone of $250 \mathrm{~Hz}$ is listed in Table 4. As indicated in Table 4, the optimal design data can be obtained when the GA parameters at pop, bit, iter $_{\max }, p c$, and $p m=80,25,500,0.6,0.05$ are used. Using this GA parameter set with two other pure tones $(550,750 \mathrm{~Hz})$, the muffler's optimal sizes with respect to various pure tones are summarized in Table 5. Using the optimal design in a theoretical calculation, three optimal STL curves with respect to the targeted frequencies are plotted in Fig. 19. As revealed in Fig. 19, the STLs are precisely maximized at the desired frequencies. Moreover, it is obvious that the STL at the higher targeted frequency will be larger than the lower one. The related mufflers' sizes with respect to three kinds of pure tones $(250,550,750 \mathrm{~Hz})$ are shown in Figs. 20-22.

C. Three-Chamber Plug Muffler

For a three-chamber plug muffler, the optimized result with respect to the pure tone of $250 \mathrm{~Hz}$ is shown in Table 6 . As indicated in Table 6, the optimal design data can be obtained at the $G A$ parameters $\left(p o p\right.$, bit $_{\text {iter }}$ max,$p c$, and $\left.p m\right)=(60,15$, $1000,0.6,0.05)$. Using this GA parameter set with two other pure tones $(550,750 \mathrm{~Hz})$, the muffler's optimal sizes with respect to various pure tones are summarized in Table 7. 
Table 5. Optimal STLs for a two-chamber plug perforated muffler with respect to various targeted frequencies (with $\Delta p$ constraint).

\begin{tabular}{|c|c|c|c|c|c|c|}
\hline Item & Targeted frequency & & & timal Re & & \\
\hline \multirow{6}{*}{1} & \multirow{6}{*}{$250 \mathrm{~Hz}$} & $A f f_{21}$ & $A f f_{22}$ & $A f f_{23}$ & $A f f_{24}$ & STL $(\mathrm{dB})$ \\
\hline & & 0.7588 & 0.3938 & 0.6984 & 0.3610 & 87.5 \\
\hline & & $A f f_{25}$ & $A f f_{26}$ & $A f f_{27}$ & $A f f_{28}$ & $\Delta \mathrm{p}(\mathrm{Pa})$ \\
\hline & & 0.8554 & 0.5540 & 0.5012 & 0.5633 & 797 \\
\hline & & Aff $f_{29}$ & $\eta_{1}$ & $d h_{1}(\mathrm{~m})$ & & \\
\hline & & 0.0914 & 0.0430 & 0.0050 & & \\
\hline \multirow{6}{*}{2} & \multirow{6}{*}{$550 \mathrm{~Hz}$} & $A f f_{21}$ & $A f f_{22}$ & $A f f_{23}$ & Aff $f_{24}$ & STL $(\mathrm{dB})$ \\
\hline & & 0.8250 & 0.5046 & 0.4914 & 0.5000 & 165 \\
\hline & & Aff $f_{25}$ & Aff $f_{26}$ & Aff $f_{27}$ & $A f f_{28}$ & $\Delta \mathrm{p}(\mathrm{Pa})$ \\
\hline & & 0.5125 & 0.5241 & 0.5000 & 0.5003 & 777 \\
\hline & & $A f f_{29}$ & $\eta_{1}$ & $d h_{1}(\mathrm{~m})$ & & \\
\hline & & 0.1166 & 0.0300 & 0.0070 & & \\
\hline \multirow{6}{*}{3} & \multirow{6}{*}{$750 \mathrm{~Hz}$} & Aff $f_{21}$ & $A f f_{22}$ & $A f f_{23}$ & Aff $f_{24}$ & $\mathrm{STL}(\mathrm{dB})$ \\
\hline & & 0.7083 & 0.5125 & 0.4750 & 0.5002 & 162 \\
\hline & & $A f f_{25}$ & $A f f_{26}$ & Aff $_{27}$ & $A f f_{28}$ & $\Delta \mathrm{p}(\mathrm{Pa})$ \\
\hline & & 0.5000 & 0.5500 & 0.5000 & 0.5000 & 507 \\
\hline & & $A f f_{29}$ & $\eta_{1}$ & $d h_{1}(\mathrm{~m})$ & & \\
\hline & & 0.0844 & 0.1000 & 0.0070 & & \\
\hline
\end{tabular}

Table 6. Optimal STLs for a three-chamber plug perforated muffler (targeted frequency: $250 \mathrm{~Hz}$ ).

\begin{tabular}{|c|c|c|c|c|c|c|c|c|c|}
\hline \multicolumn{5}{|c|}{ GA parameters } & \multicolumn{5}{|c|}{ Optimal Results } \\
\hline \multirow{2}{*}{ рор } & \multirow{2}{*}{ bit } & \multirow{2}{*}{$p m$} & \multirow{2}{*}{$p c$} & \multirow{2}{*}{ iter $_{\max }$} & $A f f_{31}$ & $A_{f f} 32$ & $A f f_{33}$ & $A f f_{34}$ & STL $(\mathrm{dB})$ \\
\hline & & & & & 0.500 & 0.7000 & 0.7000 & 0.7000 & 179.9 \\
\hline \multirow{6}{*}{60} & \multirow{6}{*}{15} & \multirow{6}{*}{0.05} & \multirow{6}{*}{0.6} & \multirow{6}{*}{1000} & $A f f_{35}$ & $A f f_{36}$ & $A f f_{37}$ & $A f f_{38}$ & $\Delta \mathrm{p}(\mathrm{Pa})$ \\
\hline & & & & & 0.700 & 0.5000 & 0.5000 & 0.5134 & 799.3 \\
\hline & & & & & $A f f_{39}$ & $A f f_{40}$ & $A f f_{41}$ & $A f f_{42}$ & \\
\hline & & & & & 0.501 & 0.5000 & 0.5000 & 0.1577 & \\
\hline & & & & & $\eta_{1}$ & $d h_{1}(\mathrm{~m})$ & & & \\
\hline & & & & & 0.030 & 0.0018 & & & \\
\hline
\end{tabular}

Notes: $A f f_{31}=\mathrm{Lz} / \mathrm{Lo} ; A f f_{32}=\mathrm{Lz} 2 / \mathrm{Lz} ; A_{f f} 3_{33}=\mathrm{Lz} 1 \mathrm{~A} / \mathrm{Lz} 1 ; A f f_{34}=\mathrm{Lz} 2 \mathrm{~A} / \mathrm{Lz} 2 ; A f f_{35}=\mathrm{Lz} 3 \mathrm{~A} / \mathrm{Lz} 3 ; A_{f f}=\mathrm{Lc} 1 \mathrm{~A} / \mathrm{Lz} 1 \mathrm{~A} ; A_{3 f}{ }_{37}=\mathrm{Lc} 1 \mathrm{~B} / \mathrm{Lz} 1 \mathrm{~B}$; $A f f_{38}=\mathrm{Lc} 2 \mathrm{~A} / \mathrm{Lz} 2 \mathrm{~A} ; A f f_{39}=\mathrm{Lc} 2 \mathrm{~B} / \mathrm{Lz} 2 \mathrm{~B} ; A f f_{40}=\mathrm{Lc} 3 \mathrm{~A} / \mathrm{Lz} 3 \mathrm{~A} ; A f f_{41}=\mathrm{Lc} 3 \mathrm{~B} / \mathrm{Lz} 3 \mathrm{~B} ; A f f_{42}=\mathrm{d} 1 / \mathrm{Do}$

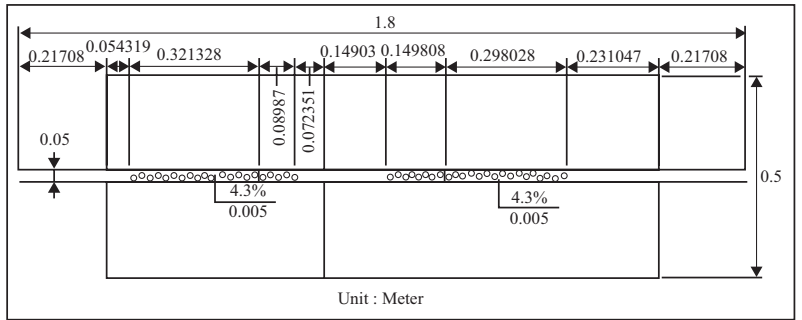

Fig. 20. Optimal shape of a two-chamber plug muffler with a targeted frequency of $250 \mathrm{~Hz}$.

Using the optimal design in a theoretical calculation, three optimal STL curves with respect to the targeted frequencies are plotted in Fig. 23. As revealed in Fig. 23, the STLs are

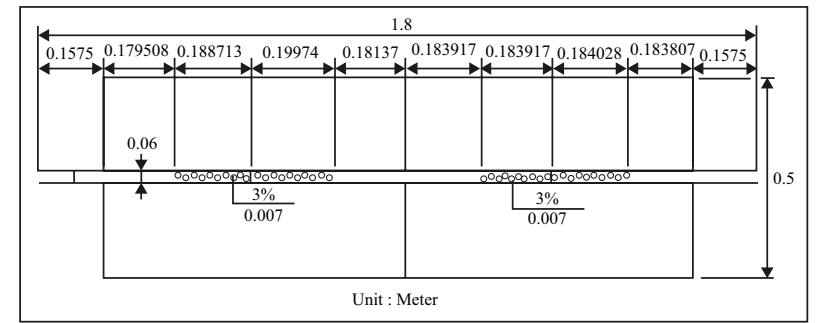

Fig. 21. Optimal shape of a two-chamber plug muffler with a targeted frequency of $550 \mathrm{~Hz}$.

precisely maximized at the desired frequencies. The related mufflers' sizes with respect to three kinds of pure tones (250, $550,750 \mathrm{~Hz}$ ) are shown in Figs. 24-26. It is obvious that the 
Table 7. Optimal STLs for a three-chamber plug perforated muffler with respect to various targeted frequencies (with $\Delta$ p constraint).

\begin{tabular}{|c|c|c|c|c|c|c|}
\hline Item & Targeted frequency & \multicolumn{5}{|c|}{ Optimal Results } \\
\hline \multirow{8}{*}{1} & \multirow{8}{*}{$250 \mathrm{~Hz}$} & $A f f_{31}$ & $A f f_{32}$ & $A f f_{33}$ & $A f f_{34}$ & STL (dB) \\
\hline & & 0.5559 & 0.6996 & 0.6996 & 0.4806 & 168.8 \\
\hline & & $A f f_{35}$ & $A f f_{36}$ & $A f f_{37}$ & $A f f_{38}$ & $\Delta \mathrm{p}(\mathrm{Pa})$ \\
\hline & & 0.3004 & 0.5008 & 0.5641 & .7804 & 798.5 \\
\hline & & $A f f_{39}$ & $A f f_{40}$ & $A f f_{41}$ & $A f f_{42}$ & \\
\hline & & 0.8984 & 0.5192 & 0.5004 & 0.1527 & \\
\hline & & $\eta_{1}$ & $d h_{1}(\mathrm{~m})$ & & & \\
\hline & & 0.0301 & 0.0046 & & & \\
\hline & & $A f f_{31}$ & $A f f_{32}$ & $A f f_{33}$ & $A f f_{34}$ & STL $(\mathrm{dB})$ \\
\hline & & 0.5876 & 0.7000 & 0.6999 & 0.4997 & 225.7 \\
\hline & & $A f f_{35}$ & $A f f_{36}$ & $A f f_{37}$ & $A f f_{38}$ & $\Delta \mathrm{p}(\mathrm{Pa})$ \\
\hline & & 0.6999 & 0.5003 & 0.5000 & 0.5001 & 799.0 \\
\hline 2 & $550 \mathrm{~Hz}$ & $A f f_{39}$ & $A f f_{40}$ & $A f f_{41}$ & $A f f_{42}$ & \\
\hline & & 0.5001 & 0.5004 & 0.5001 & 0.1558 & \\
\hline & & $\eta_{1}$ & $d h_{1}(\mathrm{~m})$ & & & \\
\hline & & 0.0300 & 0.0070 & & & \\
\hline & & $A f f_{31}$ & $A f f_{32}$ & $A f f_{33}$ & $A f f_{34}$ & STL (dB) \\
\hline & & 0.5000 & 0.6807 & 0.3000 & 0.5622 & 231.1 \\
\hline & & $A f f_{35}$ & $A f f_{36}$ & $A f f_{37}$ & $A f f_{38}$ & $\Delta \mathrm{p}(\mathrm{Pa})$ \\
\hline 3 & $750 \mathrm{~Hz}$ & 0.3000 & 0.5001 & 0.5001 & 0.7250 & 775.8 \\
\hline & & $A f f_{39}$ & $A f f_{40}$ & $A f f_{41}$ & $A f f_{42}$ & \\
\hline & & 0.5000 & 0.5005 & 0.5000 & 0.1574 & \\
\hline & & $\eta_{1}$ & $d h_{1}(\mathrm{~m})$ & & & \\
\hline & & 0.0300 & 0.0070 & & & \\
\hline
\end{tabular}

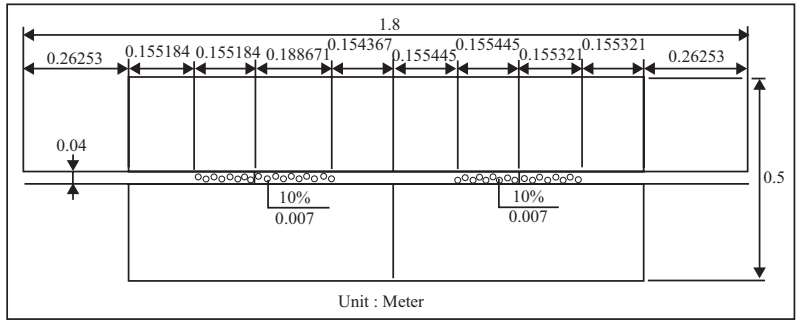

Fig. 22. Optimal shape of a two-chamber plug muffler with a targeted frequency of $750 \mathrm{~Hz}$

STL at the higher targeted frequency will be larger than that at the lower one.

\section{2) Broadband Noise Optimization}

By using the above $G A$ parameters, the optimal muffler's design data for three kinds of multi-chamber plug mufflers (a one-chamber, two-chamber, and a three-chamber) used to minimize the sound power level at the muffler's outlet is summarized in Table 8. As illustrated in Table 8, the resultant sound power levels with respect to three kinds of mufflers have been dramatically reduced from $136.3 \mathrm{~dB}(\mathrm{~A})$ to 96.2

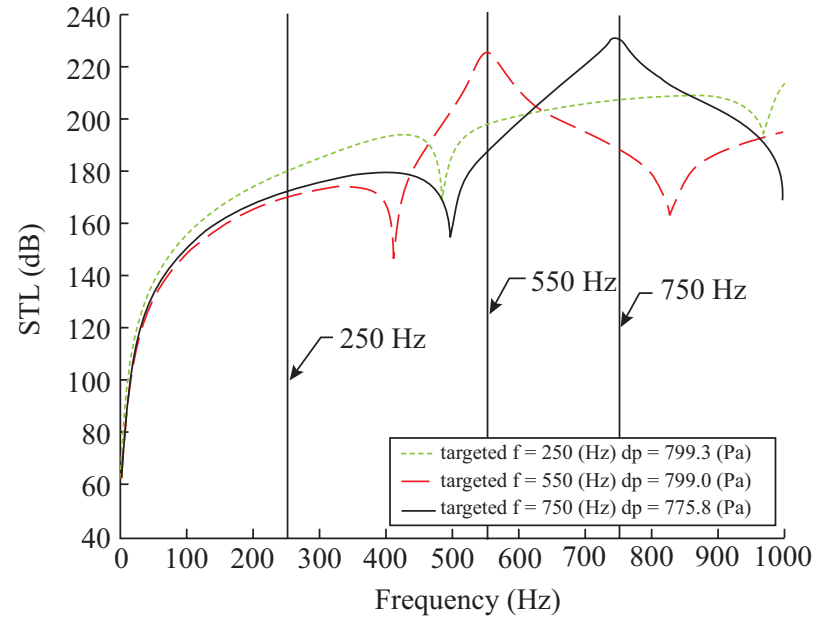

Fig. 23 Optimal STL with respect to frequencies for a three-chamber plug silencer [targeted frequency: 250,550 and $750 \mathrm{~Hz}$ ].

$\mathrm{dB}(\mathrm{A}), 53.0 \mathrm{~dB}(\mathrm{~A})$, and $11.9 \mathrm{~dB}(\mathrm{~A})$. Using this optimal design in a theoretical calculation, the resultant curves of the $S W L$ with respect to three kinds of mufflers are plotted in Fig. 27. As shown in Fig. 27, the muffler with three chambers 


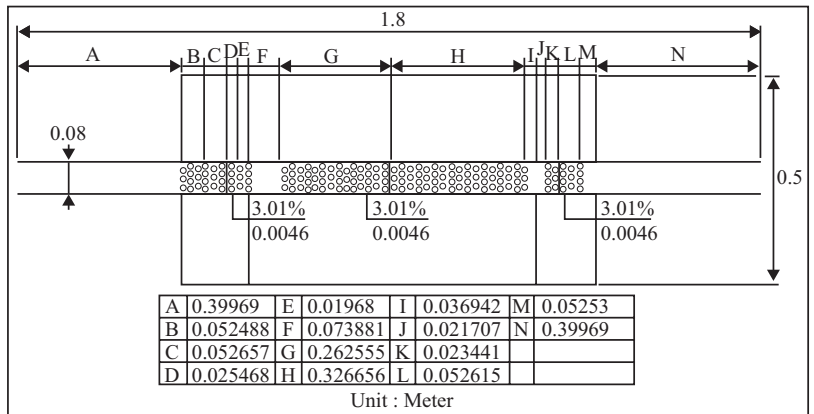

Fig. 24. Optimal shape of a three-chamber plug muffler with a targeted frequency of $250 \mathrm{~Hz}$.

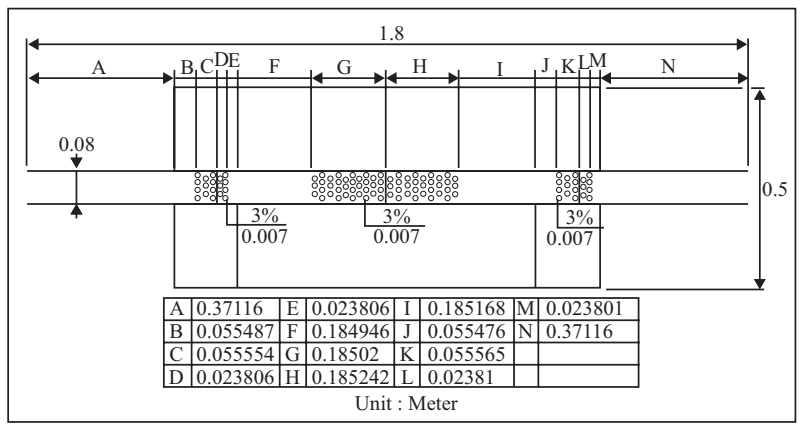

Fig. 25. Optimal shape of a three-chamber plug muffler with a targeted frequency of $550 \mathrm{~Hz}$.

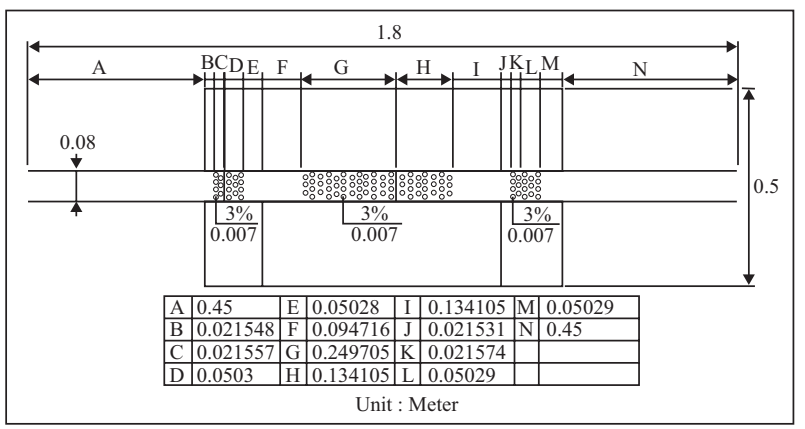

Fig. 26. Optimal shape of a three-chamber plug muffler with a targeted frequency of $750 \mathrm{~Hz}$.

obviously has the best acoustical performance. Based on plane wave theory, the proposed available theoretical cutoff frequencies of $f c_{1}\left(f_{c 1}=\frac{1.84 c_{o}}{\pi D}\left(1-M^{2}\right)^{1 / 2}\right)$ with respect to three kinds of mufflers are $964 \mathrm{~Hz}, 3220 \mathrm{~Hz}$, and $1974 \mathrm{~Hz}$. Consequently, the optimal mufflers' size is also shown in Figs. $28 \sim 30$.

\section{Discussion}

To achieve a sufficient optimization, the selection of the appropriate GA parameters set is essential. As indicated in Tables 2, 4, and 6, the best GA sets with respect to three kinds

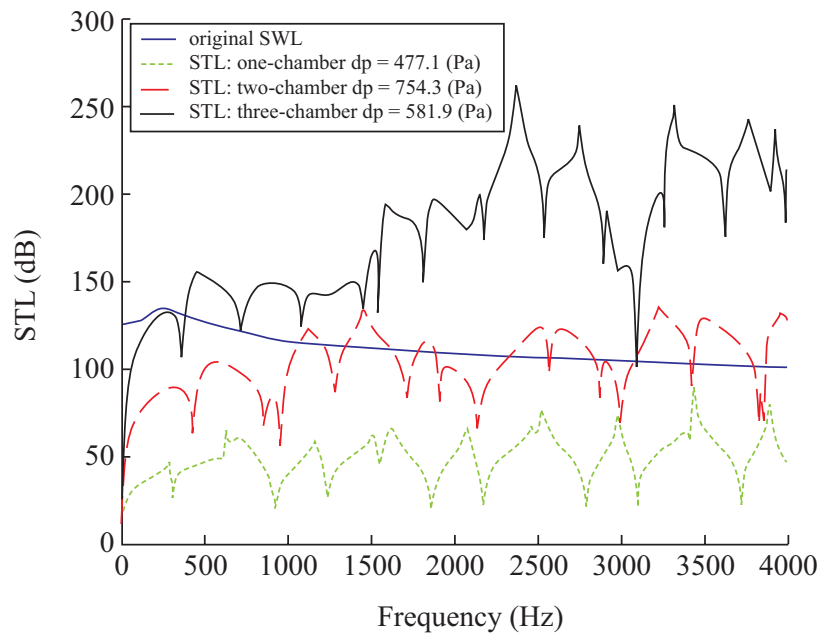

Fig. 27. A comparison of three kinds of optimal STLs with an original sound power level [broadband frequency].

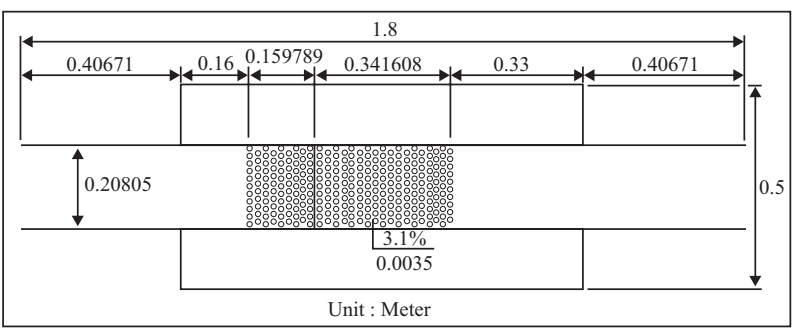

Fig. 28. Optimal shape of a one-chamber plug muffler [broadband frequency].

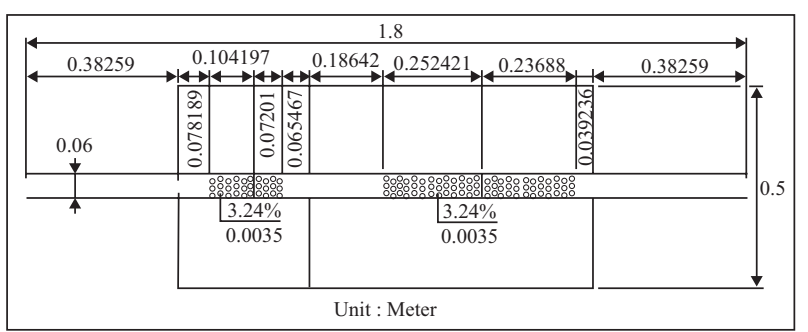

Fig. 29. Optimal shape of a two-chamber plug muffler [broadband frequency].

of mufflers (a one-chamber, two-chamber, and a three-chamber) at the targeted pure tone noise of $250 \mathrm{~Hz}$ have been shown. Using the appropriate GA sets with three kinds of mufflers at the targeted pure tones $(250,550,750 \mathrm{~Hz})$, the related optimal STL curves are plotted in Figs. 8, 19, and 23. The Figs. 8, 19, and 23 reveal the predicted maximal values of the STL are precisely located at the desired frequency. Therefore, the usage of the GA optimization in finding a better design solution is reliable; moreover, all the pressure drops calculated in various mufflers can meet the specified allowable back pressure of $800(\mathrm{~Pa})$. As described in Section VI.1.1.A, in seeking a better STL with a $\Delta$ p below the allowable maximal pressure drop, the compromise between parameters $\left(A f f_{13}, A f f_{14}, A f f_{15}\right)$ 
Table 8. Minimization of $S W L_{T}$ for a broadband noise by three kinds of plug mufflers (with $\Delta p$ constraint).

\begin{tabular}{|c|c|c|c|c|c|c|c|c|c|c|}
\hline Category & \multicolumn{5}{|c|}{ Optimal GA parameters } & \multicolumn{5}{|c|}{ Optimal Results } \\
\hline \multirow{4}{*}{ One-chamber } & \multirow{2}{*}{ рор } & \multirow{2}{*}{ bit } & \multirow{2}{*}{$p m$} & \multirow{2}{*}{$p c$} & \multirow{2}{*}{ iter $_{\max }$} & $A f f_{11}$ & $A f f_{12}$ & $A f f_{13}$ & $A f f_{14}$ & $\mathrm{SWL}_{\mathrm{T}}(\mathrm{dB})$ \\
\hline & & & & & & 0.548 & 0.319 & 0.507 & 0.509 & 96.2 \\
\hline & \multirow{2}{*}{80} & \multirow{2}{*}{10} & \multirow{2}{*}{0.05} & \multirow{2}{*}{0.6} & \multirow{2}{*}{200} & Aff 15 & $\eta_{1}$ & $d h_{1}(\mathrm{~m})$ & & $\Delta \mathrm{p}(\mathrm{Pa})$ \\
\hline & & & & & & 0.416 & 0.031 & 0.0045 & & 477.1 \\
\hline \multirow{6}{*}{ Two-chamber } & \multirow{2}{*}{ рор } & \multirow{2}{*}{ bit } & \multirow{2}{*}{$p m$} & \multirow{2}{*}{$p c$} & \multirow{2}{*}{ iter $_{\max }$} & $A f f_{21}$ & $A f f_{22}$ & $A f f_{23}$ & $A f f_{24}$ & $\mathrm{SWL}_{\mathrm{T}}(\mathrm{dB})$ \\
\hline & & & & & & 0.575 & 0.309 & 0.570 & 0.614 & 53.0 \\
\hline & \multirow{4}{*}{80} & \multirow{4}{*}{25} & \multirow{4}{*}{0.05} & \multirow{4}{*}{0.6} & \multirow{4}{*}{500} & $A f f_{25}$ & $A f f_{26}$ & $A f f_{27}$ & $A f f_{28}$ & $\Delta \mathrm{p}(\mathrm{Pa})$ \\
\hline & & & & & & 0.571 & 0.524 & 0.575 & 0.858 & 754.3 \\
\hline & & & & & & $A f f_{29}$ & $\eta_{1}$ & $d h_{1}(\mathrm{~m})$ & & \\
\hline & & & & & & 0.125 & 0.032 & 0.0035 & & \\
\hline \multirow{8}{*}{ Three-chamber } & \multirow{2}{*}{ рор } & \multirow{2}{*}{ bit } & \multirow{2}{*}{$p m$} & \multirow{2}{*}{$p c$} & \multirow{2}{*}{ iter $_{\max }$} & $A f f_{31}$ & $A f f_{32}$ & $A f f_{33}$ & $A f f_{34}$ & $\mathrm{SWL}_{\mathrm{T}}(\mathrm{dB})$ \\
\hline & & & & & & 0.689 & 0.681 & 0.576 & 0.393 & 11.9 \\
\hline & \multirow{6}{*}{60} & \multirow{6}{*}{15} & \multirow{6}{*}{0.05} & & & $A f f_{35}$ & $A f f_{36}$ & $A f f_{37}$ & $A f f_{38}$ & $\Delta \mathrm{p}(\mathrm{Pa})$ \\
\hline & & & & & & 0.353 & 0.733 & 0.5098 & 0.845 & 581.9 \\
\hline & & & & 0.6 & 1000 & $A f f_{39}$ & $A f f_{40}$ & $A f f_{41}$ & $A f f_{42}$ & \\
\hline & & & & 0.0 & 1000 & 0.552 & 0.565 & 0.5016 & 0.159 & \\
\hline & & & & & & $\eta_{1}$ & $d h_{1}(\mathrm{~m})$ & & & \\
\hline & & & & & & 0.038 & 0.007 & & & \\
\hline Notes: One-chamber & $A f f_{11}=$ & $/ \mathrm{Lo} ;$ & $2=\mathrm{Lz}$ & $\mathrm{Lz} ; A$ & $13=\mathrm{Lc} 1 \mathrm{H}$ & $f f_{14}=\mathrm{L}$ & $\mathrm{z} 1 \mathrm{~B} ; A f f_{1}$ & 11/Do & & \\
\hline Notes: Two-chamber & $\begin{array}{l}A f f_{21}= \\
\text { Lc2A/ }\end{array}$ & $\begin{array}{l}/ \mathrm{Lo} ; \\
2 \mathrm{~A} ; A\end{array}$ & $\begin{array}{l}2=\mathrm{Lz} 1 \\
=\mathrm{Lc} 2 \mathrm{I}\end{array}$ & $\begin{array}{l}\mathrm{z} ; \mathrm{Aff} \\
\mathrm{z} 2 \mathrm{~B}\end{array}$ & $\begin{array}{l}=\mathrm{Lz} 1 \mathrm{~A} / \\
f f_{29}=\mathrm{d} 1\end{array}$ & ; Aff $f_{24}=$ & $\mathrm{A} / \mathrm{Lz} 2 ; A f f$ & $\mathrm{Lc} 1 \mathrm{~A} / \mathrm{Lz} 1$ & $f_{26}=\mathrm{Lc}$ & $/ \mathrm{Lz} 1 \mathrm{~B} ; A f f_{27}=$ \\
\hline Notes: Three-chamber & $\begin{array}{l}A f f_{31}= \\
\mathrm{Lc} 1 \mathrm{~B} /\end{array}$ & $/ \mathrm{Lo}$ & $\begin{array}{l}2=\mathrm{Lz} \\
=\mathrm{Lc} 2 \mathrm{~A}\end{array}$ & $\mathrm{z} ; A f J$ & $\begin{array}{l}=\mathrm{Lz} 1 \mathrm{~A} \\
f f_{39}=\mathrm{Lc}\end{array}$ & $\begin{array}{l}; A f f 3_{4} \\
\mathrm{Lz} 2 \mathrm{~B} ; A\end{array}$ & $\begin{array}{l}\mathrm{A} / \mathrm{Lz} 2 ; A \\
\mathrm{Lc} 3 \mathrm{~A} / \mathrm{Lz}\end{array}$ & $\begin{array}{l}=\mathrm{Lz} 3 \mathrm{~A} / \mathrm{Lz} \\
A f f_{41}=\mathrm{Lc}\end{array}$ & $\begin{array}{l}f_{36}=\mathrm{Lc} \\
\mathrm{zB} ; A f f\end{array}$ & $\begin{array}{l}\text { Lz1A; Aff } 37= \\
=\mathrm{d} 1 / \mathrm{Do}\end{array}$ \\
\hline
\end{tabular}

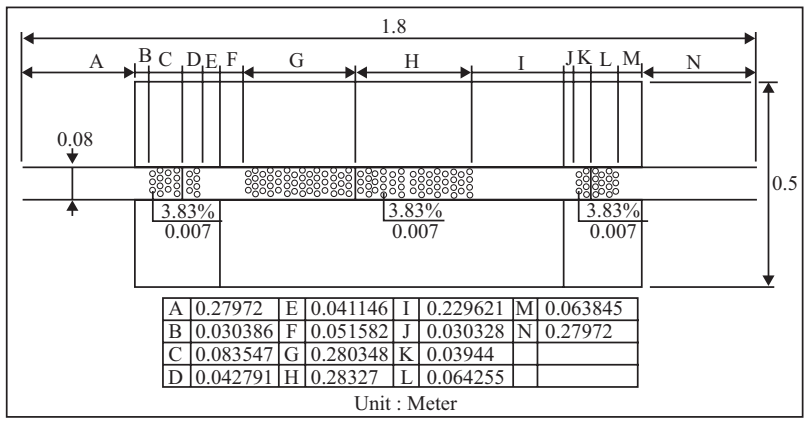

Fig. 30. Optimal shape of a three-chamber plug muffler [broadband frequency].

during the numerical optimization process is obligatory.

To appreciate the acoustical effect with respect to three kinds of chambers for various tones $(250,550,750 \mathrm{~Hz})$, the STL curves have been plotted and illustrated in Figs. 31-33. As indicated in Figs. 31-33, the muffler with the most chambers has a higher acoustical performance.

Additionally, in dealing with the broadband noise using three kinds of multi-chamber plug mufflers, the GA's solution shown in Table 8 and Fig. 27 can also provide the appropriate and sufficient sound reduction under space-constraint and $\Delta \mathrm{p}$-constrained conditions; moreover, as indicated in Fig. 27, the muffler with the most chambers can offer a higher acous-

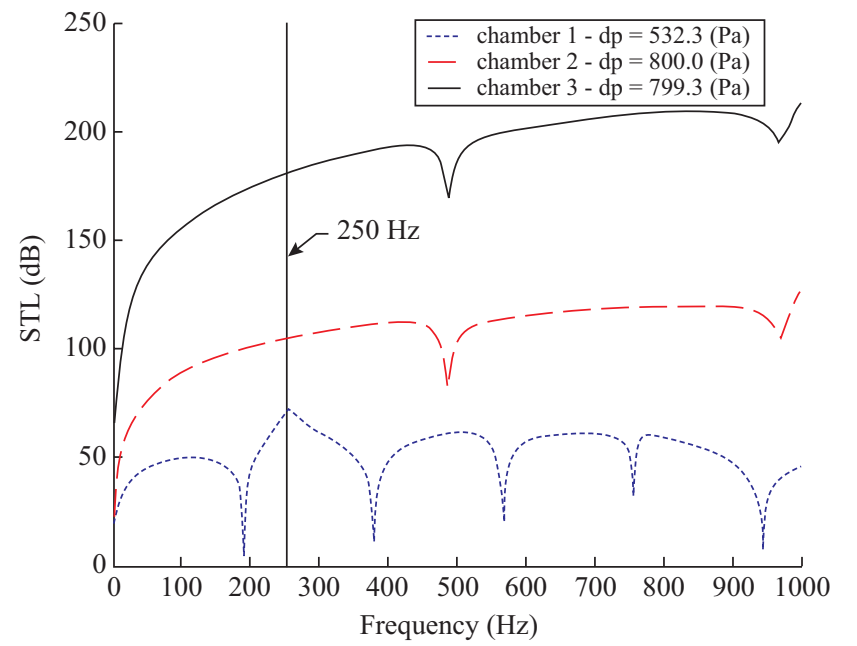

Fig. 31. Comparison of the STL with respect to various chambers [targeted frequency: $250 \mathrm{~Hz}$.

tical performance. As can be observed in Table 8, the overall sound transmission loss with respect to three kinds of mufflers reaches $40 \mathrm{~dB}, 83.0 \mathrm{~dB}$, and $124 \mathrm{~dB}$.

\section{CONCLUSION}

It has been shown that multi-chamber plug mufflers in 


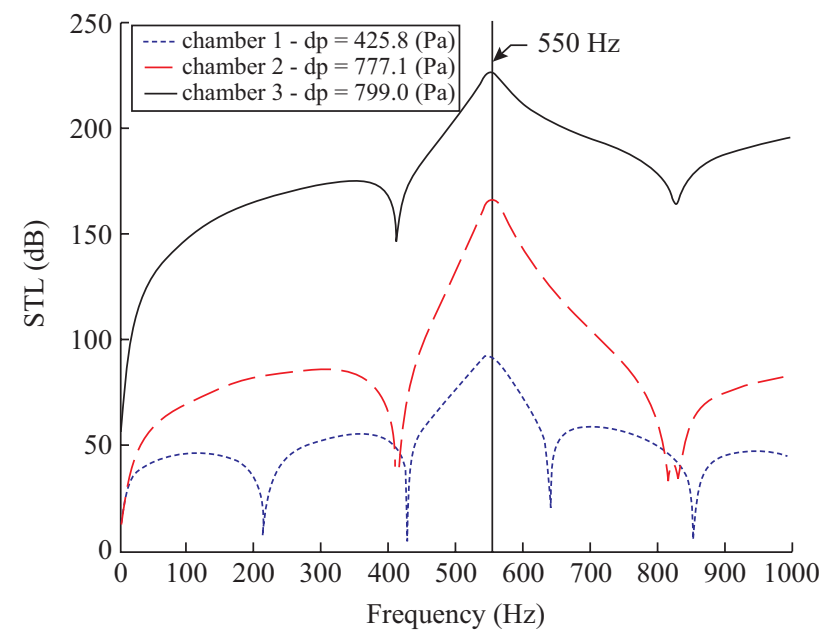

Fig. 32. Comparison of the STL with respect to various chambers [targeted frequency: $550 \mathrm{~Hz}]$.

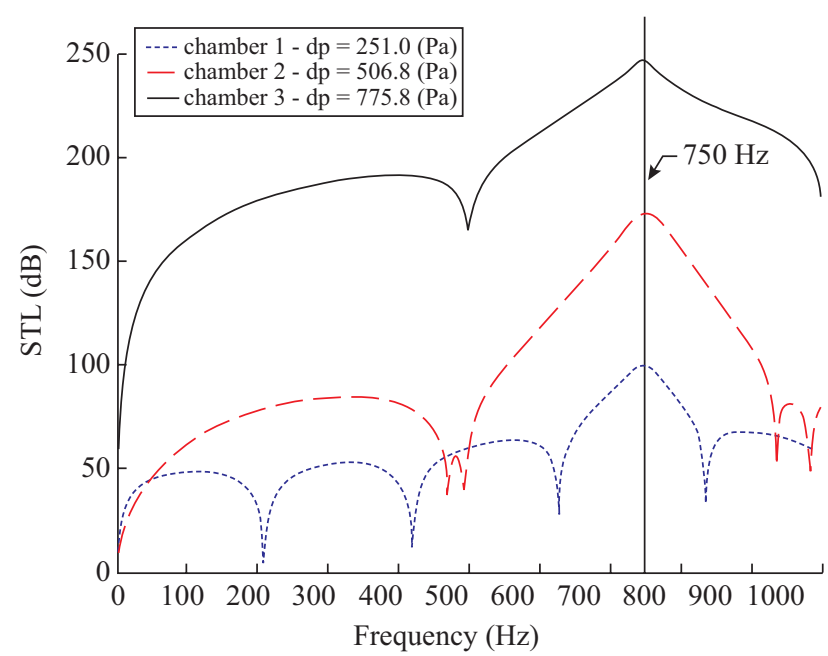

Fig. 33. Comparison of the STL with respect to various chambers [targeted frequency: $750 \mathrm{~Hz}$.

conjunction with a GA optimizer can be easily and efficiently optimized under space and $\Delta \mathrm{p}$ limits by using a generalized decoupling technique, plane wave theory, as well as a fourpole transfer matrix. Five kinds of GA parameters (pop, iter ${ }_{\max }$, $b i t, p c, p m)$ play essential roles in the solution's accuracy during GA optimization. As indicated in Figs. 8, 19, and 23, the tuning ability established by adjusting the design parameters (the lengths of perforated and non-perforated plug ducts) of three kinds of mufflers is reliable. Moreover, the figures reveal that the noise reduction in the higher targeted frequency will be easier than that in the lower one.

To appreciate the relationships between the STL, $\Delta \mathrm{p}$, and the design parameters, a one-chamber plug muffler has been investigated. It was found that the back pressure $\Delta \mathrm{p}$ will decrease noticeably when either the length of the chamber $\left(A f f_{11}\right)$, the lengths of the perforated ducts $\left(A f f_{13}, A f f_{14}\right)$, the diameter of the inner duct $\left(A f f_{15}\right)$, or the porosity of the inner duct $\left(\eta_{1}\right)$ is increased; however, some of the parameters, such as the expansion ratio $\left(A f f_{15}=\mathrm{d} 1 / \mathrm{Do}\right)$, were in conflict with respect to the STL and $\Delta \mathrm{p}$. The lower the diameter of the inner duct (d1) the more visible the increment of the STL and $\Delta \mathrm{p}$. Therefore, the compromise of $A f f_{15}$ in simultaneously obtaining a larger STL and an acceptable (smaller) $\Delta \mathrm{p}$ during the numerical optimization is necessary.

In addition, the appropriate acoustical performance curve for three kinds of multi-chamber mufflers in depressing overall broadband noise has been assessed. As indicated in Table 8 and Fig. 27, the overall sound transmission loss with respect to three kinds of mufflers reaches $40 \mathrm{~dB}, 83.0 \mathrm{~dB}$, and $124 \mathrm{~dB}$.

As investigated in Section VI, to meet the requirement of the $\Delta \mathrm{p}$ limit, a compromise between the STL and $\Delta \mathrm{p}$ is compulsory during GA optimization. Under a specified $\Delta$ p limit, a three-chamber muffler hybridized with a perforated plug duct exhibits an acoustical ability beyond other one-chamber mufflers and two-chamber mufflers that have been hybridized with perforated plug tubes. Beyond a doubt, the muffler with the most chambers will exhibit a better acoustical performance.

Consequently, the approach used for the optimal design of the $S T L$ proposed in this study within a constrained space and a back-pressure limit is indeed easy and quite effective.

\section{ACKNOWLEDGMENTS}

The authors acknowledges the financial support of the National Science Council (NSC 97-2221-E-235-001, ROC)

\section{REFERENCES}

1. Alley, B. C., Dufresne, R. M., Kanji, N., and Reesal, M. R., "Costs of workers' compensation claims for hearing Loss," Journal of Occupational Medicine, Vol. 31, pp. 134-138 (1989).

2. Chang, Y. C. and Chiu, M. C., "Shape optimization of one-chamber crossflow mufflers by GA optimization," Journal of Mechanics, Vol. 24, pp. 13-29 (2008).

3. Chang, Y. C. and Chiu, M. C., "Shape optimization of one-chamber perforated plug/non-plug mufflers by simulated annealing method," International Journal for Numerical Methods in Engineering, Vol. 74, pp. 1592-1620 (2008).

4. Chiu, M. C., "Shape optimization of double-chamber side mufflers with extended tube by using four-pole matrix and simulated annealing method," Journal of Mechanics, Vol. 24, pp. 31-43 (2008).

5. Chiu, M. C. and Chang, Y. C., "Numerical studies on venting system with multi-chamber perforated mufflers by GA optimization," Applied Acoustics, Vol. 69, No. 11, pp. 1017-1037 (2008).

6. Holland, J., Adaptation in Natural and Artificial System, University of Michigan Press, Ann Arbor, MI (1975).

7. Jayaraman, K. and Yam, K., "Decoupling approach to modeling perforated tube muffler components," Journal of the Acoustical Society of America, Vol. 69, No. 2, pp. 390-396 (1981).

8. Jong, D., An Analysis of the Behavior of a Class of Genetic Adaptive Systems, Doctoral Thesis, Department of Computer and Communication Sciences, University of Michigan, Ann Arbor, MI (1975).

9. Kaiser, L. and Bernhardt, H., "Noise control on computer and business equipment using speed control blowers," Proceedings of CompEuro '89., 'VLSI and Computer Peripherals. VLSI and Microelectronic Applica- 
tions in Intelligent Peripherals and their Interconnection Networks', pp. 2/114-2/117 (1989).

10. Magrab, E. B., Environmental Noise Control, John Wiley \& Sons, New York (1975)

11. Munjal, M. L., Acoustics of Ducts and Mufflers with Application to Exhaust and Ventilation System Design, John Wiley \& Sons, New York (1987).

12. Munjal, M. L., Krishnan, K., and Reddy, M. M., "Flow-acoustic perforated element mufflers with application to design," Noise Control Engineering Journal, Vol. 40, No. 1, pp. 159-167 (1993).

13. Munjal, M. L., Rao, K. N., and Sahasrabudhe, A. D., "Aeroacoustic analysis of perforated muffler components," Journal of Sound and Vibration, Vol. 114, No. 2, pp. 173-188. (1987).

14. Peat. K. S., "A numerical decoupling analysis of perforated pipe silencer elements," Journal of Sound and Vibration, Vol. 123, No. 2, pp. 199-212 (1988).

15. Sullivan, J. W., "A method of modeling perforated tube muffler components I: theory," Journal of the Acoustical Society of America, Vol. 66, pp. $772-778$ (1979)

16. Sullivan, J. W., "A method of modeling perforated tube muffler components I: theory," Journal of the Acoustical Society of America, Vol. 66, pp. 779-788 (1979).

17. Sullivan, J. W. and Crocker, M. J., "Analysis of concentric tube resonators having unpartitioned cavities," Journal of the Acoustical Society of America, Vol. 64, pp. 207-215 (1978).

18. Thawani, P. T. and Jayaraman, K., "Modeling and applications of straight-through resonators," Journal of the Acoustical Society of America, Vol. 73, No. 4, pp. 1387-1389 (1983).

19. Yeh, L. J., Chang, Y. C., and Chiu, M. C., "Application of genetic algorithm to the shape optimization of a constrained double-chamber muffler with extended tubes," Journal of Marine Science and Technology, Vol. 12, No. 3, pp. 189-199 (2004).

20. Yeh, L. J., Chang, Y. C., Chiu, M. C., and Lai, G. J., "Computer-aided optimal design of a single-chamber muffler with side inlet/outlet under space constraints," Journal of Marine Science and Technology, Vol. 11, No. 4, pp. 189-196 (2003). 